\title{
Improved Photodynamic Effect through Encapsulation of Two Photosensitizers in Lipid Nanocapsules
}

\author{
Alexandre Barras,$\dagger^{1 *}$ Nadia Skandrani, $\uparrow^{1,2}$ Mariano Gonzalez Pisfil, ${ }^{3}$ Solomiya Paryzhak, ${ }^{4}$ \\ Tetiana Dumych, ${ }^{4}$ Aurélien Haustrate,${ }^{5}$ Laurent Héliot, ${ }^{3}$ Tijani Gharbi, ${ }^{2,6}$ Hatem Boulahdour,, 6 \\ V'yacheslav Lehen'kyi, ${ }^{5}$ Rostyslav Bilyy, ${ }^{4}$ Sabine Szunerits, ${ }^{1}$ Gabriel Bidaux, ${ }^{3}$ and Rabah \\ Boukherroub, ${ }^{*}$ \\ ${ }^{1}$ Univ. Lille, CNRS, Centrale Lille, ISEN, Univ. Valenciennes, UMR 8520 - IEMN, F-59000 \\ Lille, France \\ ${ }^{2}$ Laboratoire de Nanomédecine, Imagerie et Thérapeutique, Université de Franche-Comté, 16 \\ Route de Gray, 25030 Besançon, France \\ ${ }^{3}$ Laboratoire de Physique des Lasers, Atomes and Molécules, Equipe Biophotonique Cellulaire \\ Fonctionnelle, Parc scientifique de la Haute Borne, Villeneuve d'Ascq, France \\ ${ }^{4}$ Danylo Halytsky Lviv National Medical University, 79010 Lviv, Ukraine \\ ${ }^{5}$ Univ. Lille, Inserm, U1003 - PHYCEL - Physiologie Cellulaire, LABEX ICST, F-59000 Lille, \\ France \\ ${ }^{6}$ CHRU Jean Minjoz, 3 Bd Alexandre Fleming, 25030 Besançon, France
}

*To whom correspondence should be addressed: alexandre.barras@univ-lille1.fr; rabah.boukherroub@univ-lille1.fr; Tel: +333 625317 24; Fax: +333 625317 01. †These authors contributed equally to this work. 


\section{ABSTRACT}

Photodynamic therapy (PDT) has developed into a new clinical and non-invasive treatment for cancer over the past 30 years. By the combination of three non toxic partners i.e. a photosensitizer (PS), molecular oxygen $\left(\mathrm{O}_{2}\right)$ and light, cytotoxic reactive oxygen species (ROS) are locally produced leading to irreversible vascular and cellular damages. In the present study, we report for the first time that the combination of two photosensitizers (2 PSs) loaded in the same lipid nanocapsules (LNCs) leads to enhanced photodynamic therapy efficiency when compared with previously reported systems. The 2 PSs-loaded LNCs are shown to increase the in vitro phototoxicity at the nanomolar range $\left(\mathrm{IC}_{50}=274\right.$ and $278 \mathrm{nM}$ on HeLa and MDA-MB-231 cell lines, respectively), whereas the corresponding single PS-loaded LNCs at the same concentration exhibit a phototoxicity two times lower. Intracellular localization in HeLa cells indicates a subcellular asymmetry of PpIX and Hy, in the plasma, ER membranes and in round internal structures. Biodistribution of LNCs was studied upon different ways of injection into swiss nude mice; based on obtained data LNCs were injected intratumorally and used to slow the grow of xenograft tumors in mice. The results obtained in this study suggest that the combination of two or more PSs may be a promising strategy to improve the efficacy of the conventional photodynamic therapy as well as to reduce dark toxicity.

Key words: Lipid nanocapsules; hypericin; protoporphyrin IX; singlet oxygen; photodynamic therapy 


\section{INTRODUCTION}

Photodynamic therapy (PDT), involving the excitation of a non-toxic photosensitizer (PS) at an appropriate wavelength in presence of molecular oxygen, has become a promising method for the treatment of tumor cells. The photochemical reactions in PDT are responsible for the formation of singlet oxygen as well as the highly reactive oxygen species (ROS) that can cause lethal damage to the targeted cells. ${ }^{1}$

Photofrin was the first PS to receive regulatory approval for PDT treatment of various cancers throughout the world, including the United States (approved by Food and Drug Administration [FDA] in $1995 .^{2}$ Even though this first-generation of PS has proven to be efficient in the treatment of various cancer types, Photofrin has some drawbacks such as low absorption of light and high photosensitivity due to the poor clearance of the compound. Therefore, to overcome these limitations, the development of improved (second-generation) PSs has been the focus of research as this would allow optimizing the amount of singlet oxygen formed and will consequently positively impact PDT. ${ }^{3}$ Ideally, the PS should absorb in the visible to the nearinfrared region with high molar extinction coefficient and high singlet oxygen quantum yields $\left(\Phi_{\Delta}\right)$. Porphyrins, a group of organic macromolecules composed of pyrrole conjugated molecules, have been chemically modified in order to increase and shift the light absorption to the nearinfrared therapeutic region and/or their solubility. Other formulations have been performed by addition of metal ions to form metallo-porphyrin complexes. In general, the second generation of PSs exhibited improved photophysical properties and allowed to address some of the shortcomings associated with the first generation PSs. Conjugation of the second generation PSs to biomolecules such as monoclonal antibodies (MAb) allowed to increase the affinity and selective delivery of the third-generation PS for malignant tissue. ${ }^{4}$ Nonetheless, to date, only three 
PS (Aminolevulinic acid (ALA) and derivatives of ALA, a prodrug of porphyrin; photofrin ${ }^{\circledR}$, a mixture of porphyrins and verteporfin, a porphyrin derivative) are FDA-approved.

Even though, the combination of PS with other active drugs (chemotherapy, immunotherapy) or techniques (radiotherapy) are good alternatives for diagnostics and enhancement of therapeutic effects, ${ }^{5}$ we believe that a simple combination of two or more PS molecules with safe lipid nanocarriers such as liposomes or lipid nanoparticles might represent an interesting approach worth of investigation.

The literature survey is limited to a few reports using the combination of free PS molecules. In 2009, Schneider-Yin et al. reported the enhancement of phototoxicity on HEC-1A cell colony formation by addition of hypericin $(60 \mathrm{nM})$ to 5 -aminolevulinic acid (5-ALA, $0.5 \mathrm{mM})$ after 10 days of post-illumination with a white light. In that case, the nanomolar concentration of hypericin may just increase the amount of protoporphyrin IX (PpIX) produced by cells during PDT treatment, as demonstrated by PpIX quantification. ${ }^{6}$ The dark toxicity of a mixture of hypericin and Foslipos ${ }^{\circledR}(1: 1)$ was studied on two different head and neck squamous cell carcinoma cell lines. ${ }^{7}$ The obtained data suggested that this combination decreases the dark toxicity effect. Nevertheless, cell viability differences between each PS alone and the mixture were not biologically significant on UMB-SCC 745 and 969 under these conditions. ${ }^{8}$ By combining two highly efficient PSs (zinc(II)-phthalocyanine and meso-tetrakis(4- $N$ methylpyridyl)porphine), Acedo et al. demonstrated a synergistic tumor cell phototoxicity on three cell lines (HeLa, HaCat and MCF-7). ${ }^{9}$

We have recently demonstrated that lipid nanocapsules (LNCs) loaded with hypericin can be successfully used in PDT experiment in vitro. ${ }^{10}$ Indeed, nanoparticles-based PDT has several advantages over traditional PDT. ${ }^{11,12}$ For example, solubility and aggregation problems of PSs in aqueous media can be overcome by encapsulating the PSs. 
Due to the high surface/area ratio of nanocarriers and the possibility to add targets onto their surface, selective targeting toward specific cells can be achieved, limiting the damage of healthy tissues. In this study, we investigate the possibility to encapsulate two PSs (hypericin and protoporphyrin IX) in lipid nanocapsules (LNCs) with the aim to achieve enhanced PDT in vitro and in vivo. The physical and photophysical properties of the resulting nanocapsules were characterized in terms of drug loading, size, charge and optical properties. Singlet oxygen yield as well as photobleaching were also evaluated. The in vitro phototoxicity was then measured on two cell lines (HeLa and MDA-MB-231). In order to understand these results, intracellular localization, kinetic measurements on endoplasmic reticulum and mitochondrial networks, and reactive oxygen species (ROS) production were performed by confocal and video-microscopies. The in vivo biodistribution and tumor evolution were finally investigated in swiss nude mice bearing xenograft tumors.

\section{EXPERIMENTAL SECTION}

Materials. Hypericin (Hy, purity $>99 \%$ ) and Protoporphyrin IX (PpIX, purity $>95 \%$ ) were provided by Planta Natural Products (Wien, Austria) and Sigma-Aldrich (Saint-Quentin Fallavier, France), respectively. A stock solution of Hy and PpIX were prepared in dimethylsulfoxide (DMSO) at $10 \mathrm{mM}$ and stored at $-20{ }^{\circ} \mathrm{C}$ in the dark. Labrafac ${ }^{\mathrm{TM}}$ Lipophile WL 1349 (caprylic/capric triglyceride), Phospholipon ${ }^{\circledR} \quad 90 \mathrm{G}$ (soybean lecithin at $97.1 \%$ of phosphatidylcholine), and Solutol® HS15 (a mixture of free polyethylene glycol 660 and polyethylene glycol 660 hydroxystearate) were generously provided by Gattefosse S.A.S. (SaintPriest, France), Phospholipid GmbH (Köln, Germany), and Laserson (Etampes, France), respectively. Deionized water was obtained from a Milli-Q plus system (Millipore, Paris, France). 
Rose bengal (RB, purity 95\%) and all other chemical reagents and solvents were obtained from Sigma-Aldrich (Saint-Quentin Fallavier, France) and used as received.

Lipid nanocapsules (LNCs) preparation. Hy and PpIX were mixed in Labrafac prior to all preparation steps. Thereafter, LNCs were formulated at a nominal size of $25 \mathrm{~nm}$ using a phase inversion method of an oil/water system, as described by Heurtault. ${ }^{13}$ Briefly, the oil phase containing Labrafac (126 mg) and Phospholipon 90G (18.75 mg) was mixed with the appropriate amounts of Solutol (204 mg), $\mathrm{H}_{2} \mathrm{O}(270 \mu \mathrm{L})$ and $\mathrm{NaCl}(22 \mathrm{mg})$, and heated under magnetic stirring up to $85{ }^{\circ} \mathrm{C}$. The mixture was subjected to 3 temperature cycles from 70 to $90{ }^{\circ} \mathrm{C}$ under magnetic stirring. Then it was cooled to $78{ }^{\circ} \mathrm{C}$ and $1.65 \mathrm{~mL}$ of distilled cold water $\left(0{ }^{\circ} \mathrm{C}\right)$ were added. The resulting suspension was stirred at room temperature for another 10 min before further use. The percentage of Hy and PpIX corresponds to the total initial mass percentage of the components of the lipid nanocapsules (i.e. $0.63 \mathrm{~g}$ ). LNCs were purified from supernatant using a disposable PD-10 desalting column (Sephadex ${ }^{\circledR}$ G-25 for gel filtration as stationary phase, Amersham Biosciences). LNCs were sterilized in $0.2 \mu \mathrm{m}$ filter syringe before cell experiments.

Particle size, zeta potential, UV-Vis and fluorescence measurements. LNCs were characterized in terms of size, surface charge and spectroscopic properties. The average diameter and polydispersity index (PI) were determined by dynamic light scattering using a Zetasizer® Nano ZS (Malvern Instruments S.A., Worcestershire, UK). The zeta potential was measured using the electrophoretic mode with the Zetasizer®. All the batches were diluted at 1/100 (v/v) in distilled water (filtered over $0.22 \mu \mathrm{m}$ ) prior to the analysis and performed in triplicate. UV-Vis measurements were carried out on a Perkin Elmer Lambda 950 dual beam spectrophotometer operating at a resolution of $1 \mathrm{~nm}$ in a $1 \mathrm{~cm}$ spectrometric cuvette. Fluorescence spectra were recorded using a Cary Eclipse spectrometer (Agilent, France) at room temperature (emission and excitation slit $5 \mathrm{~nm}$, scan rate $600 \mathrm{~nm} / \mathrm{min})$. 
Drug loading and encapsulation efficiency. LNCs were also characterized in terms of drug loading and encapsulation efficiency. The drug loading was directly determined by reversed phase - high performance liquid chromatography (RP-HPLC). RP-HPLC analyses were realized on a Shimadzu LC2010-HT (Shimadzu, Tokyo, Japan). A $5 \mu$ m C 4 QS Uptisphere® $300 \AA ̊ 2,250 \times 4.6$ mm column (Interchim, Montluçon, France) was used as the analytical column. The column was heated to $40{ }^{\circ} \mathrm{C}$. The mobile phase was a mixture of eluent A (trifluoroacetic acid $0.05 \%$ in $\mathrm{H}_{2} \mathrm{O}$ ) and eluent $\mathrm{B}$ (trifluoroacetic acid $0.05 \%$ in $\mathrm{CH}_{3} \mathrm{CN}$ ) at a flow rate of $1 \mathrm{~mL} / \mathrm{min}$. The linear gradient was 0 to $80 \%$ of eluent B in 30 min and detection was performed at $590 \mathrm{~nm}$ for Hy and at $402 \mathrm{~nm}$ for PpIX. A $10 \mathrm{mM}$ stock solution of Hy and PpIX were prepared in dimethylsulfoxide for the calibration curve. Concentrations of $1-100 \mu \mathrm{M}$ of Hy and PpIX in dimethylsulfoxide were prepared from this stock. Each sample was injected (40 $\mu \mathrm{L})$ into the RP-HPLC column. Calibration curves were obtained by linear regression of drug concentration $(\mu \mathrm{M})$ versus the peak area and are shown in Table $\mathbf{1 .}$

Table 1. Calibration curves and linear regression of Hy and PpIX

\begin{tabular}{|c|c|c|c|c|c|}
\hline Compounds & Retention time & $\begin{array}{c}\text { Regression } \\
\text { equation }^{\text {a }}\end{array}$ & $k_{\text {drug }}$ & Linear range & $\mathrm{r}^{2, \mathrm{~b}}$ \\
\hline $\boldsymbol{H y}$ & $26.6 \mathrm{~min}$ & $\mathrm{Y}=54260 \mathrm{X}$ & 54260 & $1-100 \mu \mathrm{M}$ & 0.9962 \\
\hline $\boldsymbol{P p I X}$ & $20.0 \mathrm{~min}$ & $\mathrm{Y}=373350 \mathrm{X}$ & 373350 & $1-100 \mu \mathrm{M}$ & 0.9999 \\
\hline
\end{tabular}

${ }^{a}$ Equation, where $\mathrm{Y}$ is the peak area and $\mathrm{X}$ is the concentration of compounds. ${ }^{\mathrm{b}}$ Correlation coefficient $(\mathrm{n}=5)$.

For the determination of $\mathrm{Hy}$ and PpIX encapsulation rates, LNCs were separated from supernatant using a disposable PD-10 desalting column (Sephadex ${ }^{\circledR}$ G-25 for gel filtration as stationary phase, Amersham Biosciences). The column was stabilized with $25 \mathrm{~mL}$ of distilled water. Then $2 \mathrm{~mL}$ of the LNCs suspension was deposited on the column and $0.5 \mathrm{~mL}$ of water 
were added to fill in the dead volume of the column. Finally, the LNCs were collected with $4 \mathrm{~mL}$ of distilled water as eluent. We measured Hy and PpIX concentrations by RP-HPLC before and after filtration to determine the encapsulation efficiency (EE) using the equation (1).

$$
E E(\%)=\frac{[\text { Hy or PpIX] }]_{L N C}}{[\text { Hy or PpIX }]_{\text {TOTAL }}} \times 2 \times 100
$$

where $[H y \text { or PpIX] }]_{L N C}$ is the amount of Hy or PpIX loaded in the LNCs suspension; [Hy or PpPIX] $]_{\text {TOTAL }}$ is the total Hy or PpIX amount in LNCs suspension; dilution factor of gel filtration $=2$.

Detection of singlet oxygen. The $p$-nitroso-dimethylaniline (RNO)-bleaching method was used to measure the relative ${ }^{1} \mathrm{O}_{2}$ generation efficiency of PS-loaded LNCs (Hy or PpIX or both). ${ }^{14,15}$ The ${ }^{1} \mathrm{O}_{2}$ generation efficiency was followed by the bleaching of RNO at $440 \mathrm{~nm}$ with the transannular peroxide intermediate formed as a result of the reaction between singlet oxygen and imidazole. The solution containing Hy-loaded LNC25, PpIX-loaded LNC25 and PpIX-Hy-loaded LNC25 was prepared in the presence of imidazole $(8 \mathrm{mM})$ and $\mathrm{RNO}(12.5 \mu \mathrm{M})$ in a $50 \mathrm{mM}$ phosphate buffer $(\mathrm{pH}=7.4)$. Samples in a $1 \mathrm{~cm}$ spectrometric cuvette, placed at a distance of 1.8 $\mathrm{cm}$, were irradiated at room temperature in air for $60 \mathrm{~min}$ using a visible lamp (Spot Light Source 400-700 nm, L9566-03, Hamamatsu, Japan). The intensity of the light was measured using a $\mathrm{PM} 60^{\mathrm{TM}}$ Laser Fiber Power Meter (Coherent Inc, USA) and was determined as being 0.6 W. Blue and red photo-irradiations were done using a visible lamp (Spot Light Source 400-700 nm, L9566-03, Hamamatsu, Japan). A band pass optical filter (BG7 Colored Glass Bandpass Filter, 435 - $500 \mathrm{~nm}$ ) and a long pass optical filter (FGL515 Colored Glass Longpass Filter, $515 \mathrm{~nm}$ ) were used to filter off ultraviolet/red radiations and ultraviolet/blue radiations, respectively. Blue and red light intensities were measured using a PM600TM Laser Fiber Power Meter (Coherent Inc, USA) and was determined as being $0.15 \mathrm{~W}$ and $0.45 \mathrm{~W}$, respectively. The decrease of the 
absorbance caused by RNO bleaching was monitored spectrophotometrically on a Perkin Elmer Lambda 950 dual beam spectrophotometer operating at a resolution of $1 \mathrm{~nm}$ in the region of 350$550 \mathrm{~nm}$. All measurements were performed in triplicate. In order to estimate the ${ }^{1} \mathrm{O}_{2}$ quantum yield of PS-loaded LNC25 aqueous formulations, the natural logarithm values (ln $\left.\mathrm{A} / \mathrm{A}_{0}\right)$ of RNO at $440 \mathrm{~nm}$ were plotted $v s$ the photoirradiation time and fitted with a pseudo-first-order kinetic model. The ${ }^{1} \mathrm{O}_{2}$ quantum yield of PS-loaded LNC25 in aqueous solution can be estimated using Rose Bengal $(\mathrm{RB})$ as a standard $\left(\Phi_{\mathrm{RB}}=0.76 \text { in aqueous solution }\right)^{16}$ using the equation (2). ${ }^{17}$

$$
\Phi_{L N C}=\Phi_{R B} \frac{k_{L N C}}{I_{L N C}} \frac{I_{R B}}{k_{R B}}
$$

where $\Phi_{R B}$ is the ${ }^{1} \mathrm{O}_{2}$ quantum yield of RB in an aqueous solution as standard $\left(\Phi_{R B}=0.76\right) ; k_{L N C}$ and $k_{R B}$ re the rate constants for photoreaction of RNO with PS-loaded LNC25 and RB, respectively; $I_{L N C}$ and $I_{R B}$ are the rates of light absorption by PS-loaded LNC25 and RB in aqueous solution, respectively, which are estimated by integration of the absorption bands in the region of 400-700 nm, 400-550 nm or 515-700 nm.

Cell culture. The HeLa (cervix carcinoma, human) and MDA-MB-231 (human breast adenocarcinoma) cells were maintained in DMEM supplemented with $10 \%(\mathrm{v} / \mathrm{v})$ fetal-bovine serum $(\mathrm{FBS})$ and $1 \%(\mathrm{v} / \mathrm{v})$ penicillin/streptomycin in a $5 \% \mathrm{CO}_{2}$ atmosphere at $37{ }^{\circ} \mathrm{C}$.

In vitro phototoxicity. The HeLa and MDA cells were seeded into 96 -well plates $\left(1 \times 10^{4}\right.$ cells/well) $48 \mathrm{~h}$ before experiments. Prior to incubation, cells were washed with PBS. The medium was replaced with $100 \mu \mathrm{L}$ of serum-free medium containing Hy-loaded LNC25, PpIXloaded LNC25, Hy-PpIX-loaded LNC25, and free PS (Hy and PpIX) (1\% DMSO) at concentrations ranging from 0.01 to $1 \mu \mathrm{M}$. After $8 \mathrm{~h}$ incubation, cells were washed three times with PBS and then maintained in DMEM supplemented with 10\% FBS. Cells were irradiated for 12 min using a visible lamp (Spot Light Source 400-700 nm, L9566-03, Hamamatsu, Japan). The 
intensity of the light was measured using a PM600 ${ }^{\mathrm{TM}}$ Laser Fiber Power Meter (Coherent Inc, USA) and was determined as being $10 \mathrm{~mW}$. Light positive controls (untreated cells or with blank LNC25) and dark controls were included. After $16 \mathrm{~h}$ post irradiation at $37^{\circ} \mathrm{C}$, cell viability was colorimetrically measured by performing MTT assays. After removing the medium and washing by PBS, $100 \mu \mathrm{L}$ of DMEM containing MTT solution (1:10 dilution of the $5 \mathrm{mg} \cdot \mathrm{mL}^{-1}$ fresh MTT stock solution in PBS) were added. After incubation for another $3 \mathrm{~h}$, the resulting formazan dye was dissolved in dimethylsulfoxide $(50 \mu \mathrm{L})$ and the absorbance intensity was measured by a microplate reader (PHERAstar FS, BMG LABTECH GmbH, Germany) at $570 \mathrm{~nm}$ with background subtraction at $650 \mathrm{~nm}$. Cell viability was determined as the percentage of live cells per total non-treated cells.

In a control experiment, the temperature increase of serum-free DMEM irradiated with visible light $(\lambda>400 \mathrm{~nm}, 10 \mathrm{~mW})$ for 12 min was captured by an Infrared Camera (Thermovision A40) and treated using ThermaCam Researcher Pro 2.9 software.

DNA cell cycle analysis. The cell cycle was analysed according to Sackova et al. ${ }^{18}$ Briefly, the HeLa and MDA cells were treated in the same manner as before with Hy-loaded LNC25, PpIXloaded LNC25 and Hy-PpIX-loaded LNC25 at $0.5 \mu \mathrm{M}$ for $2 \mathrm{~h}$, washed two times with PBS and irradiated with visible light $(\lambda>400 \mathrm{~nm}, 10 \mathrm{~mW})$ for $12 \mathrm{~min}$. Then, the cells were harvested at $2 \mathrm{~h}$ post irradiation, washed twice with PBS, trypsined and fixed in ice-cold $70 \%$ ethanol at $-20{ }^{\circ} \mathrm{C}$. The cell suspension was then centrifuged, washed twice with PBS and resuspended in $500 \mu \mathrm{L}$ of a PBS solution containing ribonuclease A $(200 \mu \mathrm{g} / \mathrm{mL})$ and propidium iodide $(100 \mu \mathrm{g} / \mathrm{mL})$. The cellular fluorescence of PI was detected in a linear scale using a flow cytometer (FACS) equipped with an excitation laser line at 488-633 nm. At least 10000 events were collected for each sample. The percentage of cells in $\mathrm{G}_{0}-\mathrm{G}_{1}, \mathrm{~S}$ and $\mathrm{G}_{2}-\mathrm{M}$ were calculated using MODFIT computer 
software and are represented within the histograms. Statistical difference from the untreated controls: ${ }^{*} \mathrm{p}<0.05 ;{ }^{* *} \mathrm{p}<0.01$.

Cell transfection. The HeLa cells were seeded on $35 \mathrm{~mm}$ glass bottom dishes (MatTek Corporation, USA) at $1.2 \times 10^{5}$ cells/well for $48 \mathrm{~h}$ before transfection. Cells were washed with PBS, maintained in DMEM supplemented with $10 \%$ FBS and incubated for $20 \mathrm{~h}$ in a $\mathrm{CO}_{2}$ atmosphere at $37{ }^{\circ} \mathrm{C}$ in the presence of D1ER and $4 \mathrm{mtD} 3 \mathrm{cpv}$ encoding plasmids DNA $(1.2 \mu \mathrm{g}$ per well). Plasmids DNA were added to $100 \mu \mathrm{L}$ Opti-MEM, then $3.6 \mu \mathrm{L}$ of transfection reagents (ratio 1:3 v/v DNA/FuGENE®) were added and incubated for $15 \mathrm{~min}$. The mixtures were transferred in each well and gently mixed. The day after, cells were washed with PBS, maintained in serum-free medium and incubated for $2 \mathrm{~h}$ in a $\mathrm{CO}_{2}$ atmosphere at $37{ }^{\circ} \mathrm{C}$ in the presence of PpIX-loaded LNC25, Hy-loaded LNC25 and PpIX-Hy-loaded LNC25 at $0.5 \mu \mathrm{M}$ of PS. After incubation, the cells were washed two times with PBS and maintained in dark in L-15 medium without phenol red (Life technologies) at $37{ }^{\circ} \mathrm{C}$ using a stage incubator (Life Imaging Services, Switzerland) for futher video-microcopy and live-irradiation.

Fluorescence-lifetime imaging microscopy and confocal imaging. Fluorescence-lifetime imaging microscopy (FLIM) and time-lapse imaging were performed with a Leica TCS SP5 X (Leica Microsystems, Germany) confocal head with the SMD upgrade, mounted on an inverted microscope (DMI6000, Leica Microsystems, Germany). In all experiments, a 63×/1.2NA water immersion objective was used and the confocal pinhole was set to 1 Airy.

For FLIM experiments, a 405 nm pulsed diode laser PDL 800-B (PicoQuant GMBH, Germany) was used as a laser source with a repetition rate of $10 \mathrm{MHz}$. Fluorescence was detected through a 483/32 single-bandpass filter (Semrock, USA) on Single Photon Avalanche Photodiodes (SPAD) (MPD, Italy). Single photon events were recorded by a HydraHarp 400 (PicoQuant GMBH, Germany). Measurements were made with LAS AF (Leica Microsystems, Germany), and 
SymPhoTime (PicoQuant GMBH, Germany) software. FLIM Images are $256 \times 256$. Since, for statistics issues, final images were the result of the accumulation of 120 frames acquired at 200 Hz. The final acquisition time for one TCSPC image was about $100 \mathrm{~s}$ long.

In time-lapse experiments, ER was labeled in HeLa cells using the D1ER genetically encoded biosensor, as described below. As lasers sources, a $488 \mathrm{~nm}$ laser was used for imaging, and a 594 $\mathrm{nm}$ laser was used to generate redox stress in cells via the LNCs. Time-lapse movies are composed of 60 images for a total of 4 min. Images are $512 \times 512$ with a pixel size of $0.18 \mu \mathrm{m}$ for a zoom factor of 3 .

For live-cell imaging, cells were placed on $35 \mathrm{~mm}$ glass bottom dishes (MatTek Corporation, USA), filled with L-15 medium without phenol red (Life technologies), and kept at $37{ }^{\circ} \mathrm{C}$ using a stage incubator (Life Imaging Services, Switzerland). ROS production was also measured with the DFC probe in HeLa cells loaded concomitantly with PpIX-Hy-loaded LNC25 at $0.5 \mu \mathrm{M}$ for 2 $\mathrm{h}$ by adding $2^{\prime}, 7^{\prime}$-dichlorofluorescin diacetate at $40 \mu \mathrm{M}$ for $30 \mathrm{~min}$.

Animals. Five-week-old male swiss nude mice (specific and opportunistic pathogen free, $S O P F$ ) were purchased from Charles River Laboratories. The mice were housed in cages covered with air filters in a temperature-controlled room with a 12-h light/12-h dark schedule and kept on a standard diet with drinking water available ad libitum. Studies involving animals, including housing and care, method of euthanasia, and experimental protocols, were conducted in accordance with the local animal ethical committee in the animal house (D59-00913) of the University of Lille, under the supervision of Dr V'yacheslav Lehen'kyi (Protocol: 201703021400830, Authorization: 59-009270).

\section{Biodistributions studies.}

$100 \mu \mathrm{L}$ of nanocapsules diluted in sterile PBS (5 mg/kg of Hy) were injected intraperitoneally (i.p.) and intravenously (i.v.) into the tail vein, or subcutaneously (s.c.). Animals were 
anesthetized with isoflurane/oxygen mixture and imaged before, immediately after injection, and then after 1, 2, 4, 8, 24, 48, 72 and $166 \mathrm{~h}$. In vivo tracking of hypericin-containing nanocapsules was performed with a Bruker In-Vivo Xtreme machine supplied with interline front-illuminated (FI) 16 MP CCD detector, 400W Xenon Fluorescence illuminator (excitation wavelength: 540 $\mathrm{nm}$, emission wavelength: $600 \mathrm{~nm}$ with constant exposure of 3 seconds) and module for animal warming air $37^{\circ} \mathrm{C}$. The data was analyzed by high-performance Bruker Molecular Imaging (MI) software. The data represents mirror images of the mice. To evaluate distribution of nanocapsules in organs, animals were sacrificed under anesthesia, and main organs were removed and analyzed for fluorescence attributable to hypericin.

Xenogeneic tumor model. Five-week-old male swiss nude mice were injected subcutaneously (s.c.) with $1.2 \times 10^{6} \mathrm{PC} 3-\mathrm{M}$ cells resuspended in $50 \mu \mathrm{L}$ PBS / 50 $\mu \mathrm{L}$ Matrigel (BD). The PC3-M cells were grown by subcutaneous injection of $1.2 \times 10^{6}$ cells $/ 50 \mu \mathrm{L}$ of sterile PBS with $50 \mu \mathrm{L}$ of Matrigel (BD) on flank of the mice. Tumor growth was monitored with caliper every two days by measuring its dimensions and calculating the volume. Tumor volumes were calculated as follow:

$$
\text { Tumor volume }\left(\mathrm{mm}^{3}\right)=\pi / 6 \times \text { length } \times \text { weight } \times \text { height }
$$

Nanocapsules $(100 \mu \mathrm{L})$ at a low dose of $1.25 \mathrm{mg} / \mathrm{kg}$ of PS were administered after 30 days intratumorally to mice bearing tumors with an average tumor volume of $250 \pm 50 \mathrm{~mm}^{3}$. Then, the tumors were immediately irradiated with visible light $(\lambda>400 \mathrm{~nm}, 0.35 \mathrm{~W})$ for 6 min, which correspond to the light dose of $40 \mathrm{~J} / \mathrm{cm}^{2}$. Three test groups and one control group were subjected to injection as follows LNC-Hy (group 1, n=3); LNC-PpIX (group 2, n=3); targeted, LNC-PpIXHy (group 3, n=3) and finally sterile saline (control, $n=3$ ). Tumor volume was measured with calipers every 5-7 days for a period of 53 days, and then the animals were euthanized. The efficiency of the lipid nanocapsules was evaluated by measuring the tumor volume of xenograft tumors in five/six-week-old male swiss nude mice weighing 20-25 g. 


\section{RESULTS AND DISCUSSION}

Preparation and physical characterization of PS-loaded LNC25. Three different formulations of PSs-loaded LNC25 were made: one with hypericin (Hy) at 0.04 wt \% (weight percentage of Hy over the total initial mass of components i.e. $0.63 \mathrm{~g}$ ), one with protoporphyrin IX (PpIX) at 0.045 wt \% and the third having both PS present in the same LNC25 at 0.042 wt \% (0.02 wt \% of Hy +0.022 wt \% of PpIX). The PSs-loaded LNC25 formulation was achieved by mixing the PSs with excipients at optimized concentrations using the phase inversion method as described in the Experimental section.

This method offers a good control over the nanocapsules' size (between 27 to $31 \mathrm{~nm}$ ) with monodisperse size characteristics for all batches $(\mathrm{PI}<0.17)$ (Table 2). Furthermore, the study of the behaviour of lipid nanocapsules in biological media was performed by measuring the size of the LNCs in different media (ultrapure water, PBS pH 7.4, serum-free DMEM and DMEM with serum) at room temperature $\left(25^{\circ} \mathrm{C}\right)$ and at $37^{\circ} \mathrm{C}$ after $1 \mathrm{~h}$ incubation (Figure S1). The results showed that the particle size decreases slightly in PBS, while it increases slightly in medium (with or without serum) with no visible aggregation at $25^{\circ} \mathrm{C}$, indicating the good stability of the LNCs. The two types of PS were entrapped in the LNC25 with high encapsulation efficiency (>97\%) due to their high hydrophobicity. The physicochemical properties of PS-loaded LNC25 are quasi identical to the blank LNC25; the presence of Hy or PpIX had no effect on the mean diameter and the polydispersity index. The presence of Solutol HS-15, which exposes PEG chains, confers a negative zeta potential for blank LNC25 $(-6.1 \pm 1.5 \mathrm{mV})$. This value is similar to the zeta potential of other pegylated vectors such as liposomes ${ }^{19}$ and identical to the previously reported values in the literature. ${ }^{20}$ However, the zeta potential values of PS-loaded LNC25 are more negative as compared to blank LNC25. In spite of the high hydrophobicity of Hy, the 
amphiphilic molecules are preferentially located in the layers near the membrane/water interface. $^{21,22}$ In view of the results, it seems probable that Hy, an amphiphilic compound, and PpIX, containing charged hydrophilic propionate chains, are arranged at the interface which exposes hydroxyl- and carboxyl- moieties, respectively, as shown previously with amiodarone-, quercetin- and Hy-loaded LNCs. ${ }^{10,23,24}$

Table 2. Characterization of PS-loaded lipid nanocapsules (PS-LNCs)

\begin{tabular}{|l|c|c|c|c|c|c|c|}
\hline & Hy (\%) & $\begin{array}{c}\text { PpIX } \\
(\%)\end{array}$ & $\begin{array}{c}\text { Mean } \\
\text { diameter } \\
(\mathbf{n m})\end{array}$ & PI $^{\mathbf{a}}$ & $\begin{array}{c}\text { Zeta } \\
\text { potential } \\
(\mathbf{m V})\end{array}$ & $\begin{array}{c}\text { EE of } \\
\text { Hy }(\boldsymbol{\%})\end{array}$ & $\begin{array}{c}\text { EE of } \\
\text { PpIX } \\
(\%)\end{array}$ \\
\hline LNC25 & 0 & 0 & $26.6 \pm 0.8$ & $0.088 \pm 0.006$ & $-6.1 \pm 1.5$ & - & - \\
\hline LNC25-Hy & 0.04 & 0 & $27.1 \pm 2.4$ & $0.154 \pm 0.013$ & $-19.5 \pm 2.4$ & $97 \pm 2.5$ & - \\
\hline LNC25-PpIX & 0 & 0.045 & $31.6 \pm 1.9$ & $0.172 \pm 0.024$ & $-12.6 \pm 1.9$ & - & $99 \pm 1.0$ \\
\hline LNC25-PpIX-Hy & 0.02 & 0.022 & $28.0 \pm 3.3$ & $0.137 \pm 0.018$ & $-18.6 \pm 3.0$ & $98 \pm 1.6$ & $100 \pm 0.3$ \\
\hline
\end{tabular}

${ }^{a}$ Polydispersity Index mean $\pm \mathrm{SD}, \mathrm{n}=3$

The UV/Vis absorption spectra of Hy-loaded LNC25, PpIX-loaded LNC25 and PpIX-Hyloaded LNC25 are examined in the 300-700 $\mathrm{nm}$ range and are compared to those of the corresponding free molecules when dissolved in DMSO (Figure 1 and S2). Major absorption bands for Hy (Figure S2A) are found in the range of 300-400, 450-500 and 550-600 nm for both free (dissolved in DMSO) and encapsulated Hy. The shape of absorption spectra of Hy-loaded LNCs is identical to that of free Hy in DMSO. A major influence of the absorption measurements between 300 and $500 \mathrm{~nm}$ is due to the turbidity of the suspended LNCs that causes light scattering. The characteristic absorptions of Hy in DMSO correspond to an intense band at 599 $\mathrm{nm}$ and a less intense band at $555 \mathrm{~nm}$. A hypsochromic shift of $3 \mathrm{~nm}$ in absorption maxima can 
be observed due to different molecular environment surrounding the Hy molecule and solvent. ${ }^{25-}$ ${ }^{27}$ For PpIX in DMSO, the UV/Vis absorption spectrum is dominated by the characteristic porphyrin Q-bands in the range of 450-650 and B-band (Soret band). In DMSO, where PpIX is a monomer, ${ }^{28}$ the intense B-band is located at $407 \mathrm{~nm}$, together with four weaker Q-bands at 504, 539, 573, and $628 \mathrm{~nm}$ (Figure S2B). The absorption spectrum of PpIX-loaded LNC25 displays a strong B-band at $407 \mathrm{~nm}$ and four weaker Q-bands at 505, 539, 576, and $631 \mathrm{~nm}$, confirming the presence of PpIX in monomer form. For the mixture of Hy and PpIX encapsulated in LNC25, the absorption bands are the sum of Hy-loaded LNC25 and PpIX-loaded LNC25 bands with no significant shift (Figure 1A). This spectroscopic study of PS-loaded LNC25 dispersed in water suggests a good solubilization of both molecules in the lipid core of LNCs. The comparison of Hy, PpIX and Hy-PpIX-loaded LNC25 are summarized in Figure 1B.
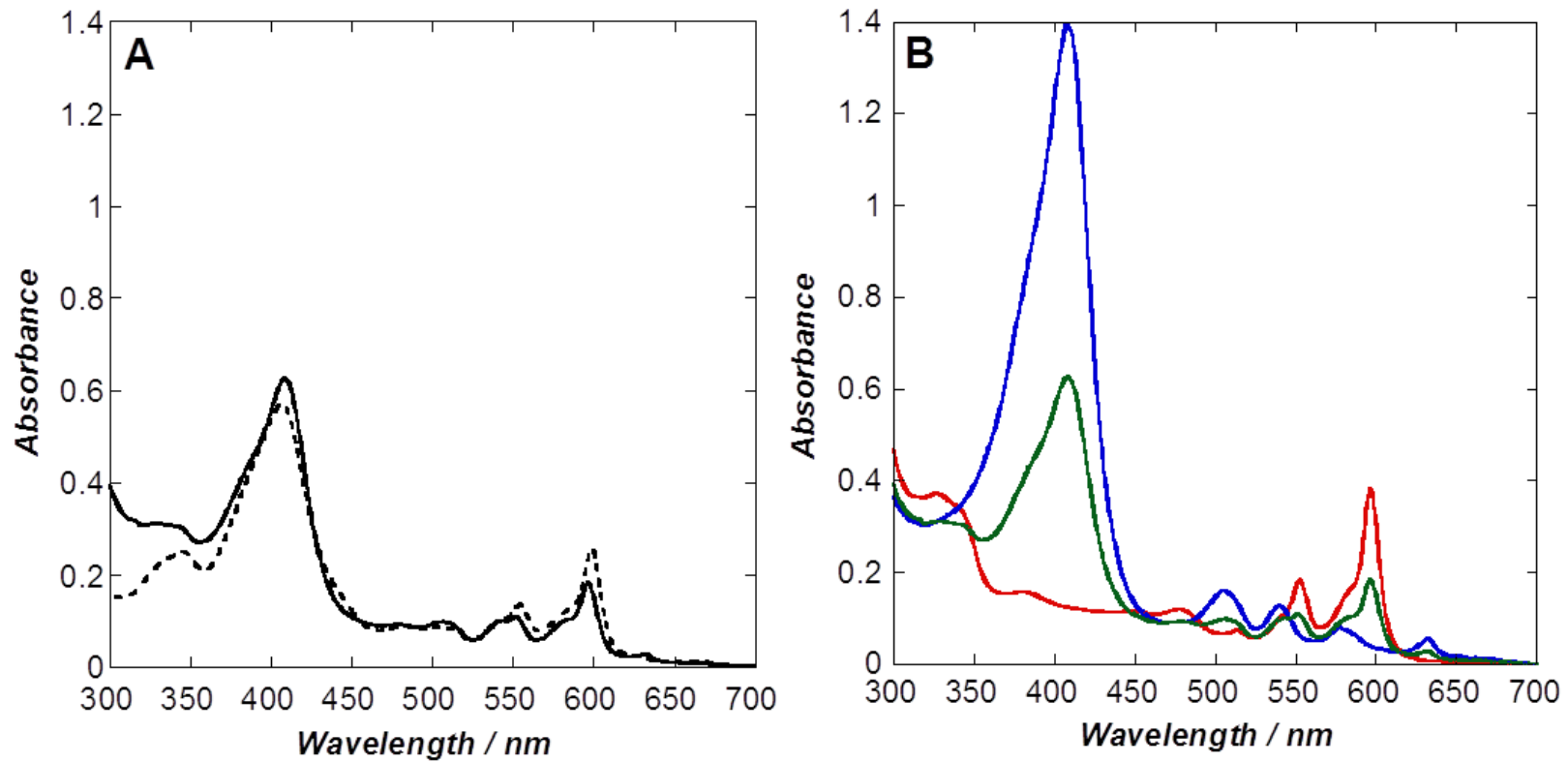

Figure 1. Absorption spectra (300 - $700 \mathrm{~nm})$ of PpIX $(5 \mu \mathrm{M})+\mathrm{Hy}(5 \mu \mathrm{M})$ dissolved in DMSO (dotted line) and PpIX-Hy-loaded LNC25 (continuous line) in water at $10 \mu \mathrm{M}(\mathbf{A})$; Comparison of Hy-loaded LNC25 (red line), PpIX-loaded LNC25 (blue line) and PpIX-Hy-loaded LNC25 (green line) (B). 
The fluorescence emission spectra of Hy-loaded LNC25, PpIX-loaded LNC25 and PpIX-Hyloaded LNC25 between 550 and $750 \mathrm{~nm}$ are seen in Figure 2 and S3 and were compared to the corresponding free molecules in DMSO. In the case of free Hy and Hy-loaded LNC25, a fluorescence emission is observed between 550 and $750 \mathrm{~nm}$ using an excitation wavelength at $330 \mathrm{~nm}$ (Figure S3A). In pure DMSO, Hy displays two emission bands located at 602 and 652 $\mathrm{nm}$, in accordance with previously reported data. ${ }^{29} \mathrm{Hy}$ dissolved in LNCs exhibits also two emission bands located at 599 and $649 \mathrm{~nm}$. The hypsochromic shift ( $3 \mathrm{~nm})$ in emission bands is due to the different molecular environment surrounding the Hy molecule and the solvent used. ${ }^{27}$ It is known that a blue shift corresponds to the decrease of the solvent polarity from DMSO to Labrafac. Interestingly, Hy-loaded LNC exhibit approximatively the same fluorescence intensity at the same concentration compared to free Hy in DMSO. All together, the results suggest that Hy encapsulation in LNCs enhances its solubilisation and the fluorescence emission is predominated by the monomeric form of Hy molecules inside the nanocapsules.

The emission spectra of PpIX using an excitation wavelength at $410 \mathrm{~nm}$ are depicted in Figure S3B. The emission spectrum of free PpIX in DMSO shows two fluorescence bands at 631 and $699 \mathrm{~nm}$, in accordance with previously reported data. ${ }^{30}$ The emission spectrum PpIX-loaded LNC25 displays strong fluorescence emission bands at 634 and $701 \mathrm{~nm}$, confirming PpIX monomer form in these LNCs. ${ }^{31}$ The fluorescence emission spectra of PpIX before and after encapsulation are almost the same in term of intensity; however after encapsulation slight changes can be observed. The emission peaks, which had red-shift $3 \mathrm{~nm}$ compared with the emission peaks of free PpIX in DMSO, can also be attributed to the the difference in molecular environment surrounding the PpIX molecule. The fluorescence measurements of the PS mixture in DMSO or encapsulated in LNC25 using an excitation wavelength of 330 or $410 \mathrm{~nm}$ (Figure 
2A and 2B) reveal that the spectra correspond to the sum of Hy and PpIX emission peaks (see supplementary information: Figure S4). The fluorescence peak at $670 \mathrm{~nm}$, resulting from the formation of PpIX photoproduct, is completely missing after encapsulation. ${ }^{32}$
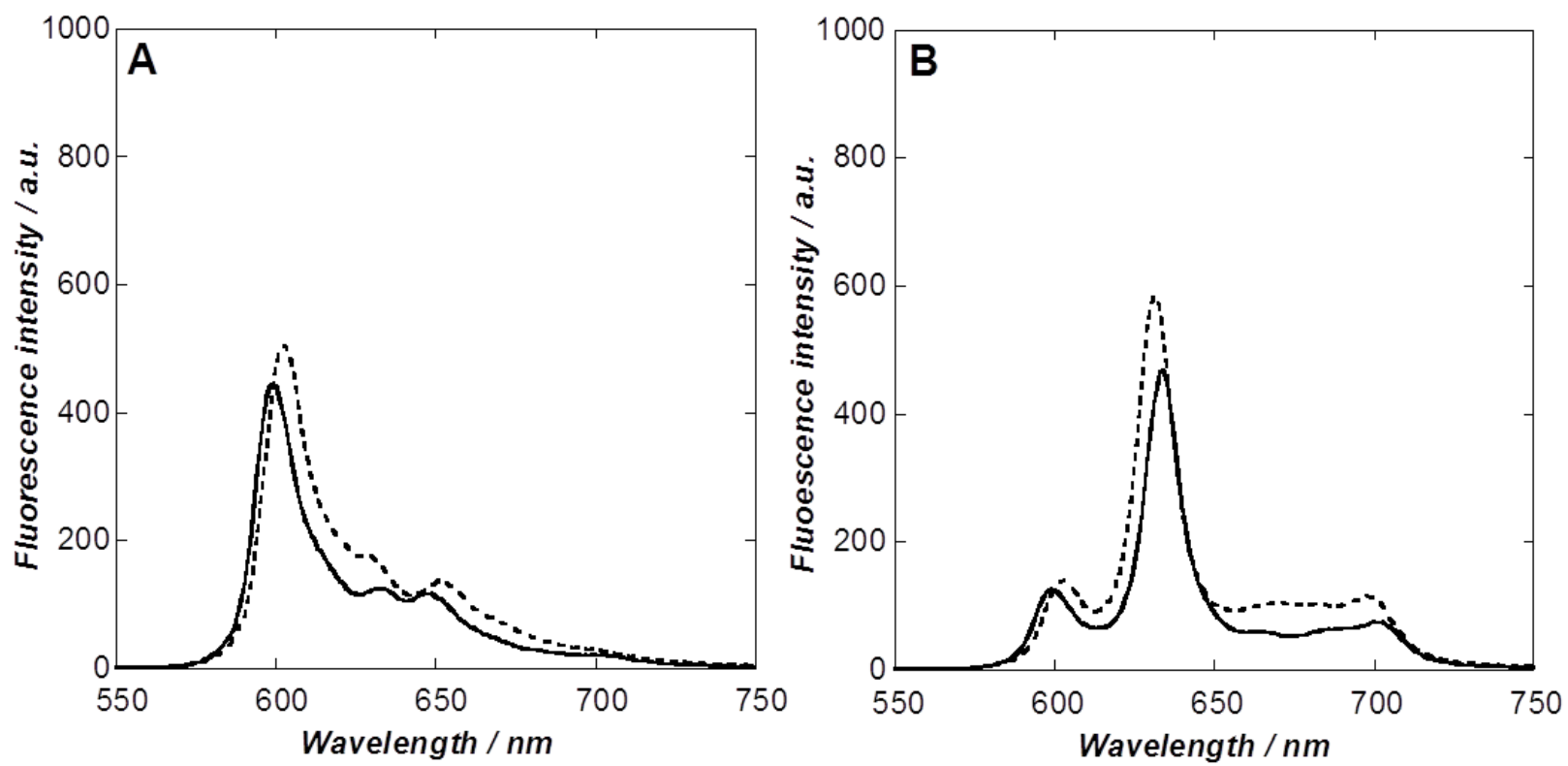

Figure 2. Fluorescence emission spectra (550-750 nm) of PpIX $(1.25 \mu \mathrm{M})+\mathrm{Hy}(1.25 \mu \mathrm{M})$ dissolved in DMSO (dotted line) and PpIX-Hy-loaded LNC25 (continuous line) in water at 2.5 $\mu \mathrm{M}$. The emission spectra are recorded using an excitation wavelength $\lambda_{\mathrm{ex}}=330 \mathrm{~nm}$ (A) and 410 $\mathrm{nm}(\mathbf{B})$.

Generation of singlet oxygen and quantum yield of PS-loaded LNC25. The amount of singlet oxygen generated can be determined quantitatively by using the $p$-nitroso-dimethylaniline (RNO) method as described previously. ${ }^{10}$ The method is based on the "bleaching" of RNO induced by the reaction of singlet oxygen with imidazole as selective acceptor. The formation of singlet oxygen is determined by following the absorbance decrease at $440 \mathrm{~nm}$. Control experiments using blank LNC25 indicate no singlet oxygen generation for concentrations up to $0.72 \mathrm{mg} \mathrm{mL}^{-1}$ after $60 \mathrm{~min}$ irradiation at $\lambda>400 \mathrm{~nm}$ (data not shown). In the case of PS-loaded LNC25 with a PS concentration of $0.5 \mu \mathrm{M}$, irradiation at $\lambda>400 \mathrm{~nm}$ at different time intervals 
(Figure 3A) resulted in a significant amount of singlet oxygen for all investigated formulations. This is contrast to free PS (1\% DMSO) in phosphate buffer condition, where almost no singlet oxygen generation is observed. PpIX-loaded LNC25 exhibit the highest production yield of singlet oxygen compared to PpIX-Hy-loaded LNC25 and Hy-loaded LNC25 at the same PS concentration (Table 2). The hydrophobic molecular environment inside the LNCs suppresses PS aggregation and water-induced quenching of singlet oxygen. Singlet oxygen is generated without release of PS directly from the nanocapsules and the level of active singlet oxygen is higher than that of free molecules. The slope of the curve in Figure 3B is a good indication of the efficiency of generated singlet oxygen. The production rate of PpIX-loaded LNC25 is higher than Hy-loaded LNC25 within $10 \mathrm{~min}$, whereas the Hy-loaded LNC25 reach a saturation after $60 \mathrm{~min}$.
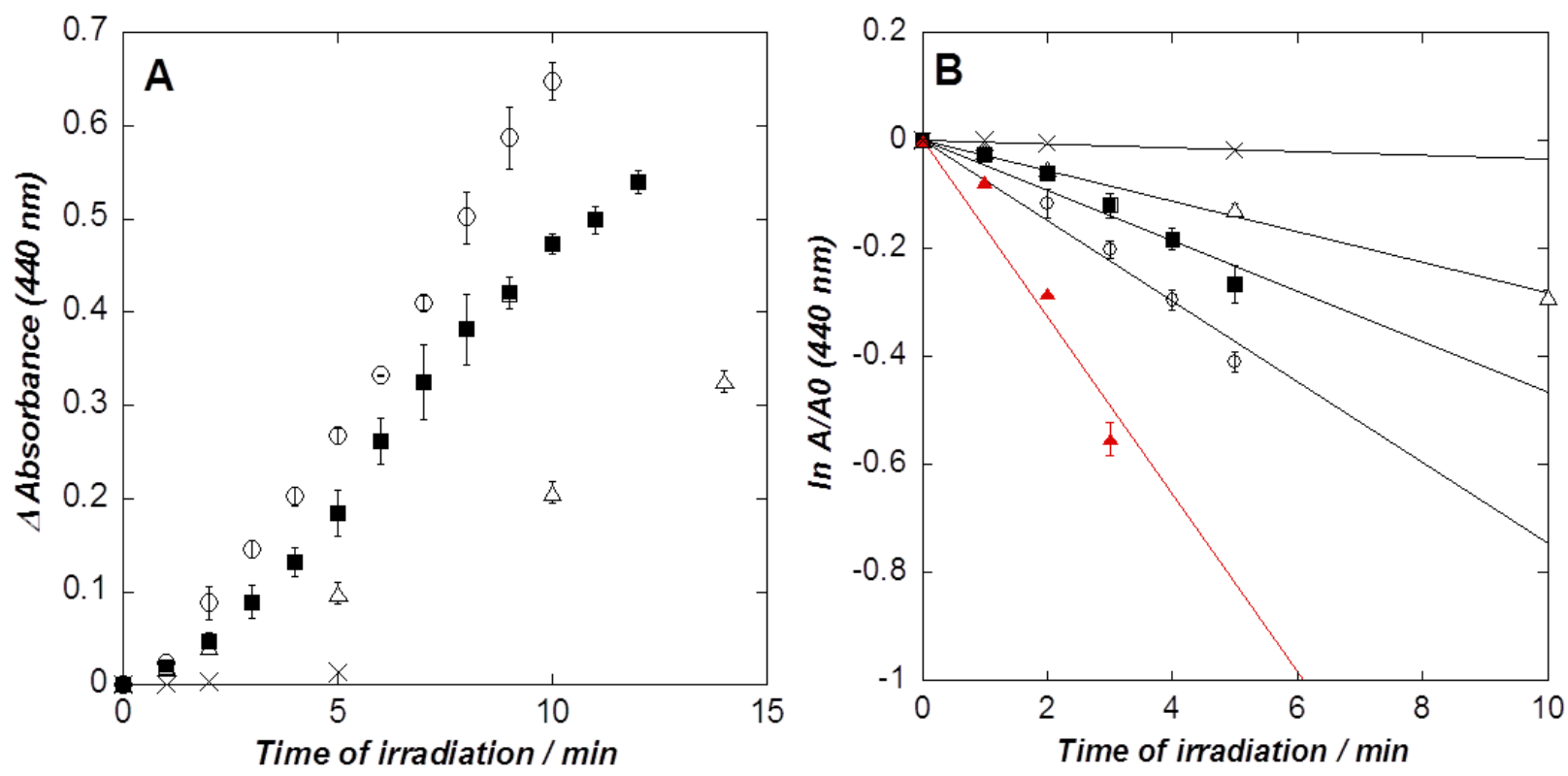

Figure 3. Generation of singlet oxygen $(\Delta \mathrm{A}$ at $440 \mathrm{~nm})(\mathbf{A})$ and pseudo first order plots of $\ln \left(\mathrm{A} / \mathrm{A}_{0}\right)(\mathbf{B})$ from photo-irradiated Hy-loaded LNC25 (open triangles), PpIX-loaded LNC25 (open circles), PpIX-Hy-loaded LNC25 (black squares) and free PpIX-Hy (1\% DMSO) (black cross $)$ at $0.5 \mu \mathrm{M}$ in a $50 \mathrm{mM}$ phosphate buffer $(\mathrm{pH}=7.4)$ as a function of irradiation time. $\mathrm{RB}$ (red triangles) as reference. 
The quantum yield of singlet oxygen generation of PS-loaded LNC25 is estimated using the comparative method where Rose Bengal (RB) is used as a standard photosensitizer reference $\left(\Phi_{\mathrm{RB}}=0.76\right) .{ }^{16}$ As described above, the depletion of RNO by ${ }^{1} \mathrm{O}_{2}$ is monitored at $440 \mathrm{~nm}$ and plots of $\ln \left(\mathrm{A} / \mathrm{A}_{0}\right)$ as a function of irradiation time can be fitted with a pseudo-first order kinetics (Figure 3B). The rate of ${ }^{1} \mathrm{O}_{2}$ generation is obtained from the slope of the pseudo-first-order plots. A similar plot is generated for $\mathrm{RB}$ as a standard photosensitizer reference and the ${ }^{1} \mathrm{O}_{2}$ quantum yields of PS-loaded LNC25 in aqueous solution are estimated using equation (2). The results are summarized in Table 3.

Table 3. Pseudo-first-order kinetic parameters and quantum yields of ${ }^{1} \mathrm{O}_{2}$ determined at $0.5 \mu \mathrm{M}$ for PS-LNC25 with different irradiations (mean $\pm \mathrm{SD}, \mathrm{n}=2$ ).

\begin{tabular}{|l|c|c|c|c|}
\hline & $\begin{array}{c}\text { Rate constants } \\
k_{\text {obs }}\left(\mathrm{min}^{-1}\right)^{\mathrm{b}}\end{array}$ & $\begin{array}{c}\text { Quantum } \\
\text { yields } \Phi^{\mathrm{b}}\end{array}$ & $\begin{array}{c}\text { Quantum } \\
\text { yields } \Phi^{\mathrm{c}}\end{array}$ & $\begin{array}{c}\text { Quantum } \\
\text { yields }^{\mathrm{d}}\end{array}$ \\
\hline Hy-loaded LNC25 & $-0.029 \pm 0.001$ & $0.38 \pm 0.01$ & $0.16 \pm 0.01$ & $0.28 \pm 0.01$ \\
\hline PpIX-loaded LNC25 & $-0.074 \pm 0.005$ & $0.31 \pm 0.02$ & $0.11 \pm 0.01$ & $0.22 \pm 0.02$ \\
\hline PpIX-Hy-loaded LNC25 & $-0.046 \pm 0.006$ & $0.32 \pm 0.04$ & $0.22 \pm 0.01$ & $0.52 \pm 0.02$ \\
\hline PpIX-Hy & -0.004 & 0.03 & n.d. & n.d. \\
\hline RB & $-0.164 \pm 0.007$ & $0.76^{\mathrm{a}}$ & $0.76^{\mathrm{a}}$ & $0.76^{\mathrm{a}}$ \\
\hline
\end{tabular}

${ }^{a}$ Literature value ${ }^{16}$

${ }^{\mathrm{b}}$ Visible irradiation $(400-700 \mathrm{~nm})$

${ }^{\mathrm{c}}$ Blue irradiation $(400-550 \mathrm{~nm})$

${ }^{\mathrm{d}}$ Red irradiation $(515-700 \mathrm{~nm})$

n.d., not determined.

The quantitative estimation of ${ }^{1} \mathrm{O}_{2}$ generation varies in the range of $0.31-0.38$ by comparing the first-order reaction rate constants of RNO bleaching with PS-loaded LNC25 and RB. For encapsulated Hy, the quantum yield compares well with the quantum yields of $0.35-0.43$ reported for ${ }^{1} \mathrm{O}_{2}$ generation by Hy entrapped in liposomes. ${ }^{33-35}$ The values are much higher than $\Phi=0.02$ reported for free Hy in water. ${ }^{36}$ For encapsuled PpIX, the quantum yield agrees well with the 
quantum yields of 0.36 reported for ${ }^{1} \mathrm{O}_{2}$ generation by PpIX perfectly dissolved with Triton $\mathrm{X}$ 100 in Tris- $\mathrm{HCl}$ buffer in order to induce monomerization. ${ }^{37}$ Thus, the LNCs seem to be a good alternative not only to solubilize Hy, but also PpIX. Finally, the values obtained for PpXI-loaded LNC25 are quite similar. We also checked the wavelength dependence of the quantum yield upon two different irradiation wavelengths. Table 3 shows the values of quantum yield determined from the photodegradation of RNO bleaching with PS-loaded LNC25 and RB. Upon blue and red irradiation, the $\Phi$ values obtained for PpXI-Hy-loaded LNC25 provide a better quantum yields of ${ }^{1} \mathrm{O}_{2}$ in comparison with single PS encapsulated in LNCs.

Photobleaching of PS-loaded LNC25. Upon irradiation, the PS are chemically modified or degraded. This phenomenon, called photobleaching, occurs by a direct attack of singlet oxygen or reactive oxygen species (ROS) on the PS. ${ }^{38}$ Experimentally, photomodification (also referred to as photoproduct formation) and photodegradation (destruction) can be followed by a decrease in fluorescence emission and/or absorbance of PS in solution, cells or tissues during light exposure. The kinetics of photobleaching of PS-loaded LNC25 in phosphate buffer is determined by spectrophotometric analysis (Figure 4A-C). The results of photobleaching of PpIX and Hy by irradiation of Hy-loaded LNC25, PPIX-loaded LNC25 and PPIX-Hy-loaded LNC25 at $5 \mu \mathrm{M}$ in $50 \mathrm{mM}$ phosphate buffer as a function of time are displayed in comparison with the free molecules dissolved in DMSO (Figure 4D-E). The results indicate a continuous decrease in absorbance of the bands without the appearance of new bands and suggests a phototransformation and a photodestruction of both PS under irradiation over time. For PpIX photobleaching study (Figure 4D), there is no significant difference in the rate of photodegradation for PpIX when it is encapsulated alone or with Hy inside the lipid nanocapsules. However, the photobleaching is faster compared to free PpIX dissolved in DMSO. As shown in Figure 4E, the rate of Hy 
photobleaching is slightly faster when it is encapsulated in LNCs compared to the free molecule in DMSO. Moreover, the photodegradation of Hy increases with time when co-encapsulated with PpIX in the lipid nanocapsules. The higher photodegradation of the remaining Hy by PpIX inside LNC may be beneficial during PDT treatment since photobleaching may induce photosensibility of the patient for an extended period of time. ${ }^{38,39}$ On the other hand, upon blue and red light irradiation, the photodegradation of Hy slightly decreases with time when co-encapsulated with PpIX in the lipid nanocapsules (data not shown).
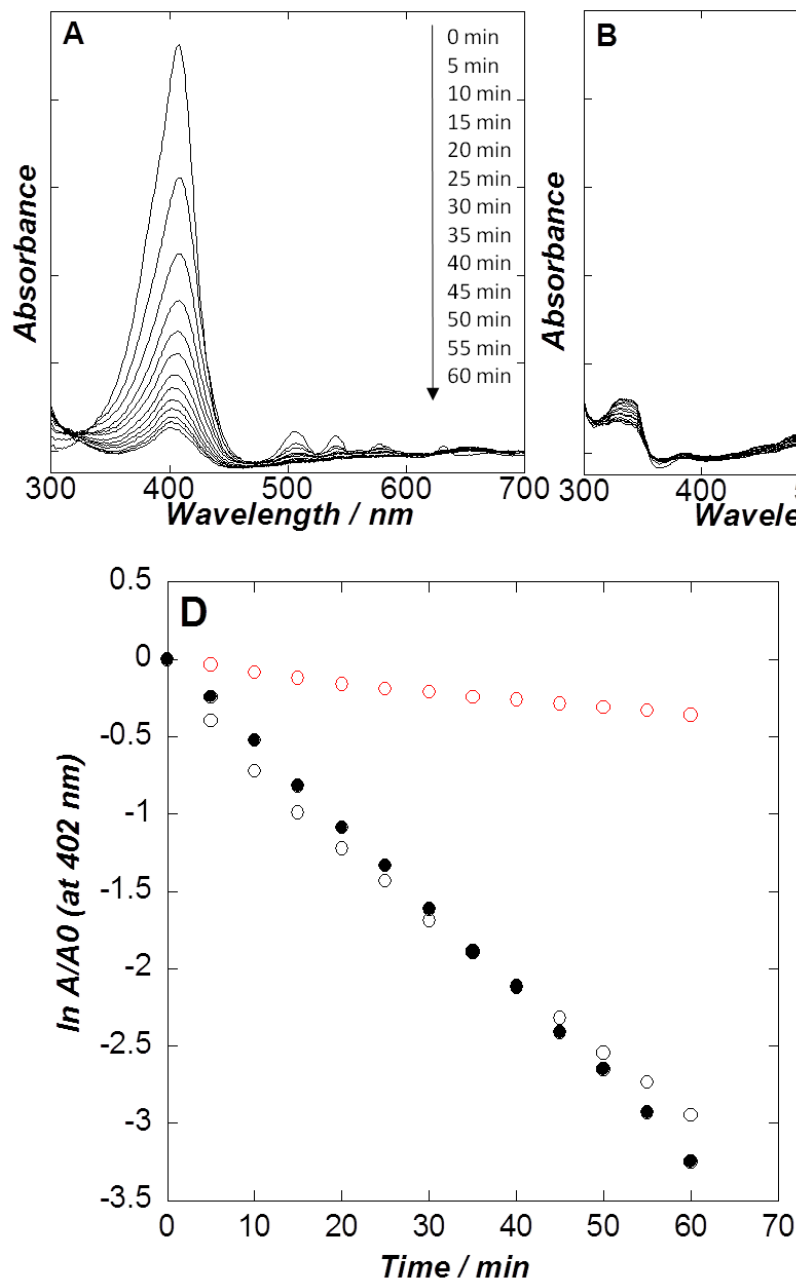
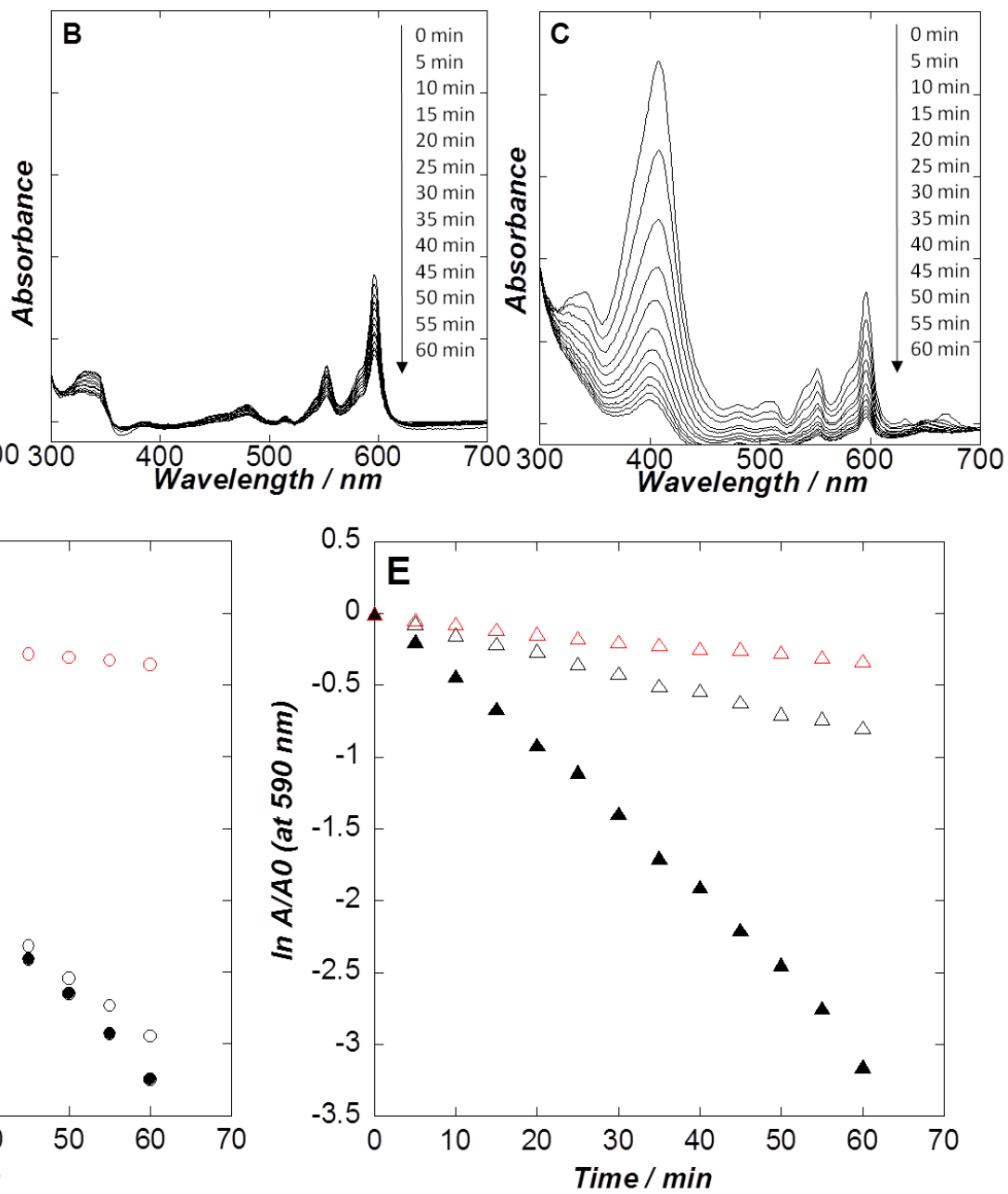

Figure 4. Effect of photoillumination on the absorption spectra of PpIX-loaded LNC25 (A), Hyloaded LNC25 (B) and PpIX-Hy-loaded LNC25 (C) at $5 \mu \mathrm{M}$ of each PS in $50 \mathrm{mM}$ phosphate buffer as a function of irradiation time (400-700nm). Rate of change of maximum absorbance of 
PpIX at $402 \mathrm{~nm}$ at $5 \mu \mathrm{M}$ : free molecule dissolved in DMSO (red circles), PpIX-loaded LNC25 (open circles) and PpIX-Hy-loaded LNC25 (black circles) (D); rate of change of maximum absorbance of Hy at $590 \mathrm{~nm}$ at $5 \mu \mathrm{M}$ : free molecule dissolved in DMSO (red triangles), Hyloaded LNC25 (open triangles) and PpIX-Hy-loaded LNC25 (black triangles) (E) in 50 mM phosphate buffer as a function of irradiation time.

In vitro phototoxicity. The cytotoxicity of PS-loaded LNC25 is assessed against HeLa cervical cancer cells and MDA-MB-231 breast cancer cells (Figure 5). The viability of cells upon photoirradiation $(\lambda>400 \mathrm{~nm}, 10 \mathrm{~mW}, 12 \mathrm{~min})$ is evaluated by MTT colorimetric assay. Cell cytotoxicity is measured as the percentage of the viable cells over the untreated cell control (without LNC25). During PDT treatment with visible light $(\lambda>400 \mathrm{~nm}, 10 \mathrm{~mW})$, the temperature increase of serum-free medium was less than $1.6 \pm 0.1^{\circ} \mathrm{C}$ after 12 min irradiation (Figure S5). This result confirmed that heat generated during PDT is negligible and has no impact on cell viability. For blanck LNC25, both cell lines did not show any observable phototoxicity or dark toxicity up to $400 \mu \mathrm{g} / \mathrm{mL}$ for incubation time of $8 \mathrm{~h}$ (see supplementary information: Figure S6). The cells are incubated with Hy-loaded LNC25, PpIX-loaded LNC25 and PpIX-Hy-loaded LNC25 for $8 \mathrm{~h}$ at concentrations ranging from $0.01 \mu \mathrm{M}$ to $1 \mu \mathrm{M}$ of PS and then washed to remove non-associated PS prior to irradiation. Figure 5 shows changes in cell viability caused by different treatments. Under dark conditions, cytotoxicities of PS-loaded LNCs are negligible. Cells survival by MTT colorimetric assay is $>95 \%$ for all formulations except a small cytotoxicity for PpIX at 0.5 and $1 \mu \mathrm{M}(>85 \%)$ for both cell lines. Also, a small cytotoxicity is found for $\mathrm{Hy}$ at 0.5 and $1 \mu \mathrm{M}(>85 \%)$ on MDA cell line. But used in combination, no cytotoxicity is observed for the PpIX-Hy-LNC25 up to $1 \mu \mathrm{M}$ for both cell lines.

Photodynamic treatments with Hy-loaded LNC25 and PpIX-loaded LNC25 exhibit a dosedependent effect on HeLa and MDA-MB-231 cells. Indeed, the $\mathrm{IC}_{50}$ of Hy-loaded LNC25 for 
HeLa and MDA-MB-231 is 0.62 and $0.56 \mu \mathrm{M}$, respectively. Similarly, PpIX-loaded LNC25 displays an $\mathrm{IC}_{50}$ of $0.55 \mu \mathrm{M}(\mathrm{HeLa})$ and $0.50 \mu \mathrm{M}$ (MDA-MD-231). Interestingly, the in vitro photodynamic therapy effect of both PS encapsulated in LNCs (PpIX-Hy-loaded LNC25) displays a substantially higher phototoxicity for both cell lines in the nanomolar range $\left(\mathrm{IC}_{50}=274\right.$ and 278 $\mathrm{nM}$ for HeLa and MDA-MB-231 cell lines, respectively). Thus, these 2PS-loaded LNCs are shown to increase the phototoxicity and provide a synergistic effect in the combined nanoparticulate system, whereas the corresponding single PS-loaded LNCs at the same concentration exhibit a phototoxicity two times lower. Furthermore, this system allows to reduce the dark toxicity on both cell lines in comparison with 50/50 molar ratio of free Hy/PpIX (see supplementary information, Figure S7).
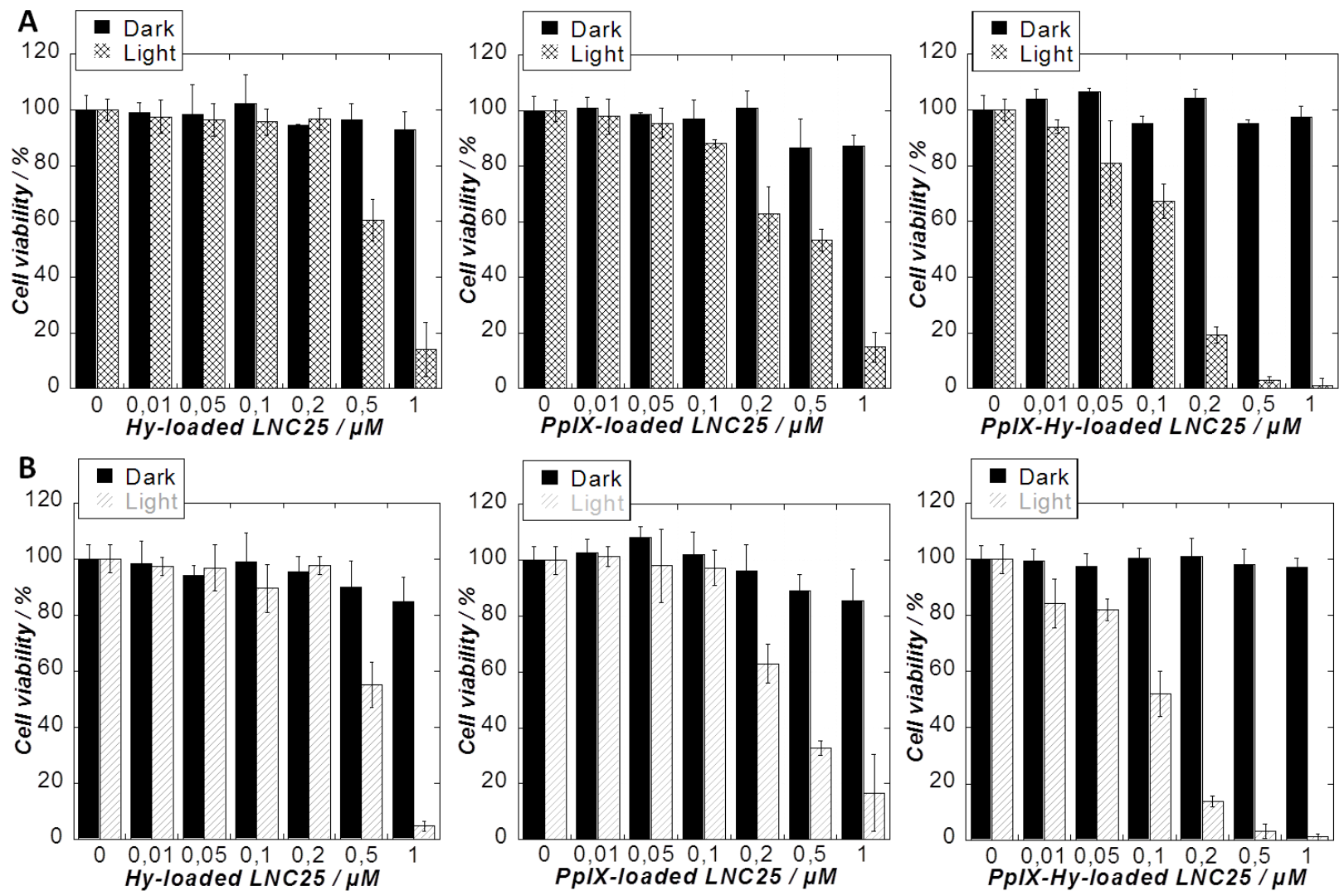

Figure 5. In vitro phototoxicity of PS-loaded LNC25. MTT assay data for cells, Hy-loaded LNC25, PpIX-loaded LNC25 and PpIX-Hy-loaded LNC25: 50/50 molar at different 
concentrations (incubation time $8 \mathrm{~h}$ ) in the dark or upon visible light irradiation (12 min at 10 $\mathrm{mW}$ ) of the HeLa cell culture (A) and MDA-MB-231 cell culture (B).

DNA cell cycle analysis. After $2 \mathrm{~h}$ incubation of MDA-MB-231 and HeLa cells with PpIXloaded LNC25, Hy-loaded LNC25 and PpIX-Hy-loaded LNC25 at $0.5 \mu \mathrm{M}$, both cells were irradiated and treated. The cellular DNA flow cytometric analysis displays the percentage of cells in $\mathrm{G}_{0}-\mathrm{G}_{1}, \mathrm{~S}$ and $\mathrm{G}_{2}-\mathrm{M}$ phases (Figure 6 and S8). An increase in the proportion of cell into cell cycle ( $\mathrm{S}$ or G2-M phases) is observed in both cell lines treated with the PS-loaded LNC25. This suggests that cell cycle is either slowed down or arrested during DNA replication (both cell lines) in addition of G2-M checkpoint (HeLa). Several studies reported that ROS-mediated DNA damage induces such an increase of cells engaged in cell cycle. ${ }^{40,41}$ By analogy, it is likely that PpIX or Hy photoactivation induces DNA damage through the production of singlet oxygen.
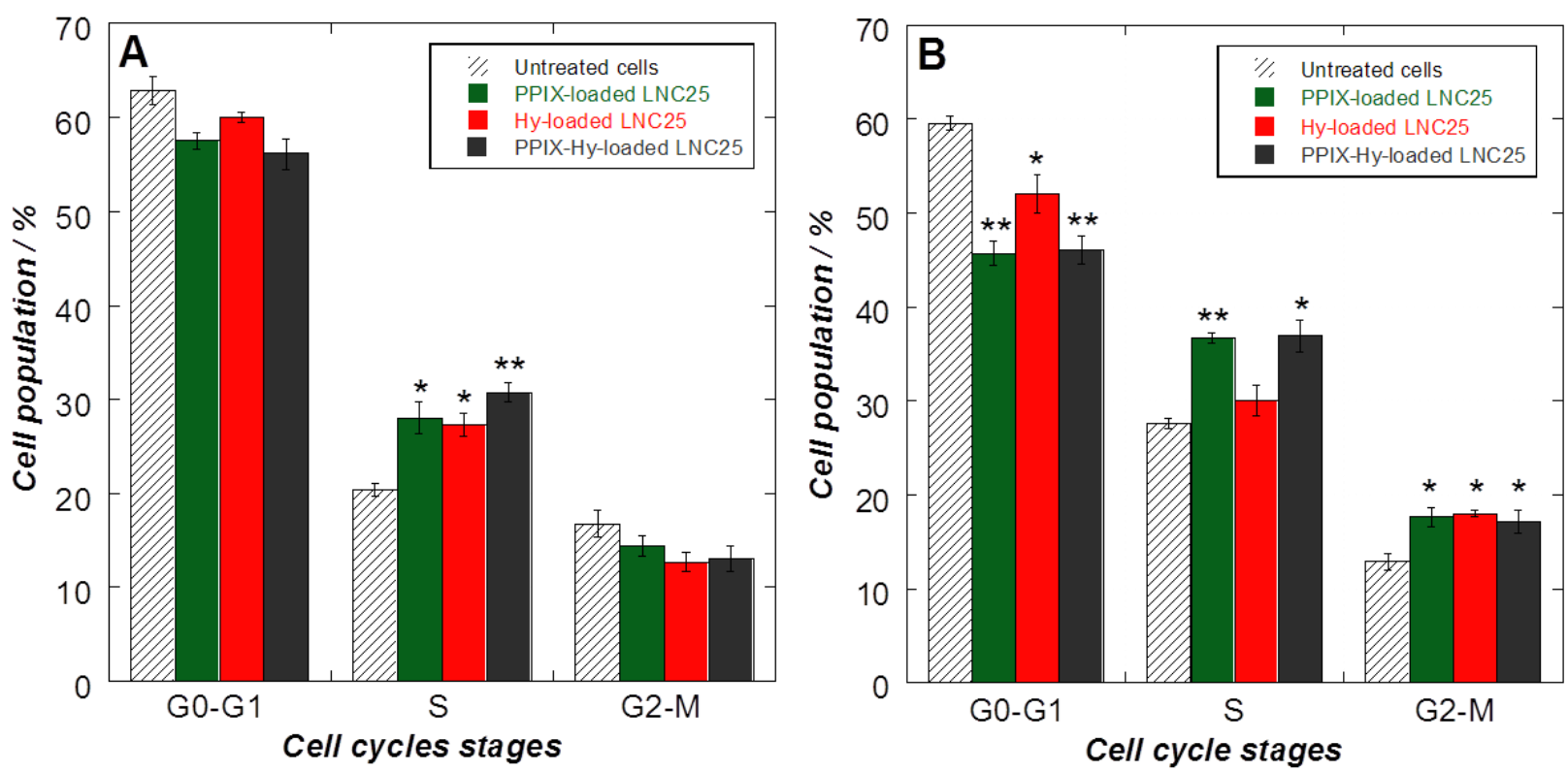

Figure 6. DNA flow cytometric analysis. The cells (A) MDA-MB-231 and (B) HeLa are treated with PS-loaded LNC25 at $0.5 \mu \mathrm{M}$ and irradiated with visible light $(10 \mathrm{~mW})$ for $12 \mathrm{~min}$. After fixation and staining with PI, the cells are analysed by flow cytometry. The percentage of cells in 
$\mathrm{G}_{0}-\mathrm{G}_{1}, \mathrm{~S}$ and $\mathrm{G}_{2}-\mathrm{M}$ are calculated using MODFIT computer software and are represented within the histograms. Statistical difference from the untreated controls: ${ }^{*} \mathrm{p}<0.05 ;{ }^{* *} \mathrm{p}<0.01$.

Cellular consequences of singlet oxygen production. To further explore a mechanistic explanation of the synergistic PDT effect in vitro, the intracellular localization of PS-loaded LNC25 is studied by fluorescence microscopy. Under a $405 \mathrm{~nm}$ excitation source, PpIX-mediated photon emission is very low. Besides, since fluorescence emission spectra of both PpIX and Hy are too narrow (Figure 2), we performed fluorescent lifetime imaging (FLIM). After treatment of cells with $0.5 \mu \mathrm{M}$ PpIX-loaded LNC25, Hy-loaded LNC25 or PpIX-Hy-loaded LNC25 for $2 \mathrm{~h}$, the samples are observed as described in the methods section. Averaged fluorescence lifetimes of PpIX and Hy are found to be about 10 and 6 ns, respectively. This important difference in lifetime facilitates the discrimination of both agents. 


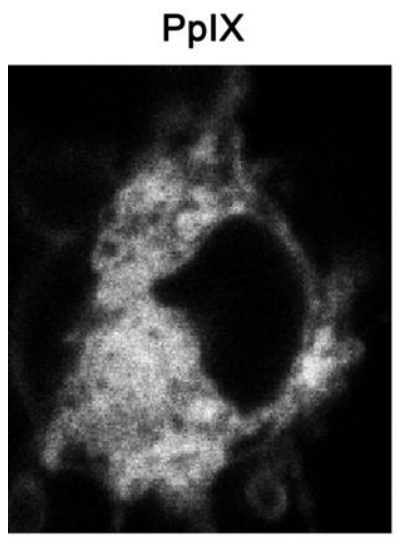

PplX

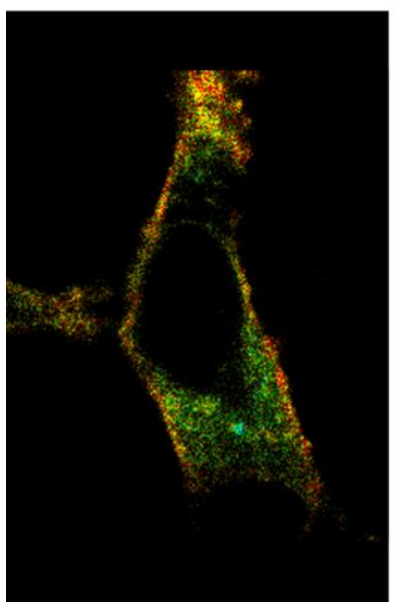

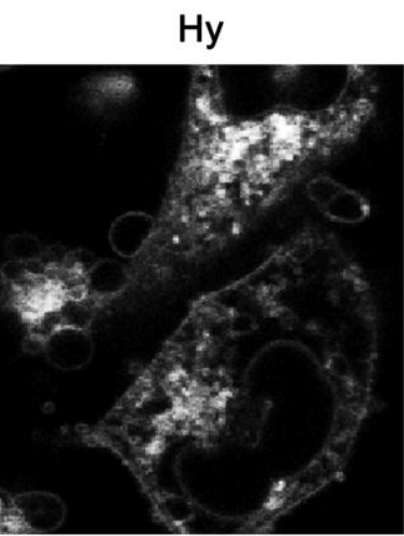

Hy
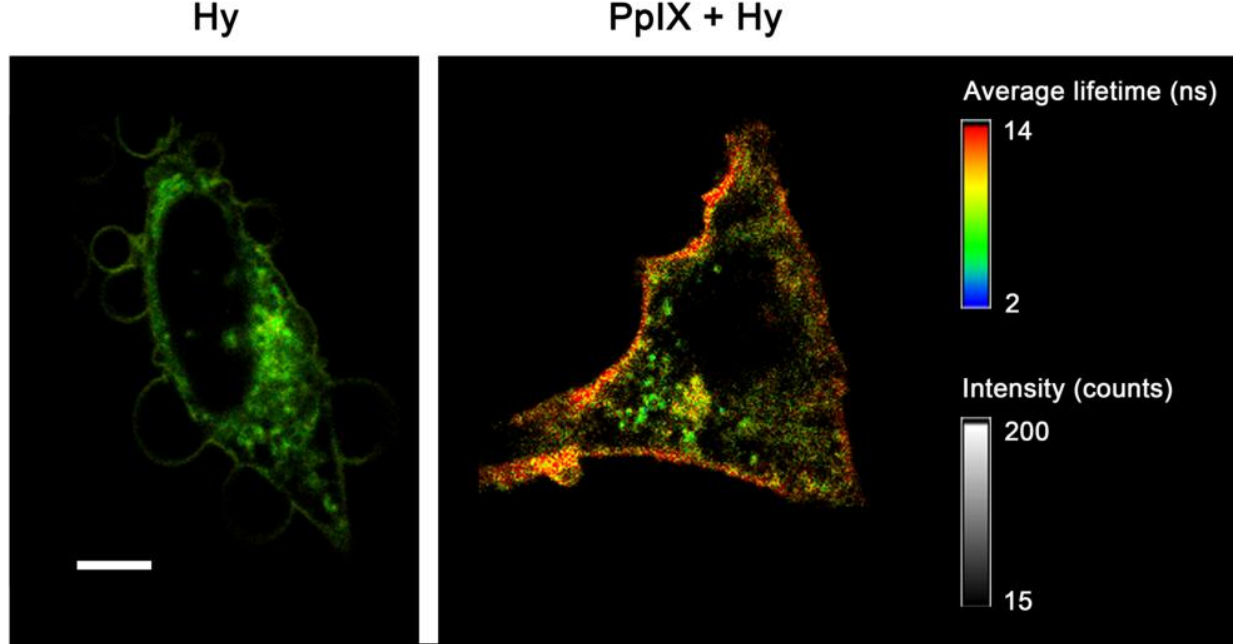

Figure 7. Intracellular localization of PS-loaded LNC25 $(0.5 \mu \mathrm{M})$ after $2 \mathrm{~h}$ of incubation in HeLa cells. Images show the average fluorescence lifetime (color bar) and fluorescence intensity (brightness as photon count intensity) of cells treated with PpIX-loaded LNC25 (PpIX), Hyloaded LNC25 (Hy) and PpIX-Hy-loaded LNC25 (PpIX + Hy). Objective: $\times 60$. Scale bar: $5 \mu \mathrm{m}$.

These results demonstrate a difference in PpIX and Hy subcellular localization (Figure 7). Indeed, while PpIX is mainly retained in the plasma and ER membranes, Hy mostly accumulates around the internal structures. Although, we do not exclude that a fraction of Hy also reached ER membranes, the colocalization studies between Hy and ER or mitochondria-target fluorescent biosensors revealed that Hy-overloaded structures are neither in ER nor in mitochondria (Figure S9). The size and number of these Hy-loaded structures, their exclusion from mitochondria and 
ER organelles and an indirect measure of hypericine effect on lysosomes activity in erythrocytes, ${ }^{42}$ suggest that Hy likely accumulates in lysosomes. PpIX lifetime shifted upon its localization in plasma membrane or in internal membranes, suggesting that its immediate environnement modifies its properties. A previous study suggested that under photoconversion, PpIX induced strong modifications in ER and mitochondria shape and network organization. ${ }^{43}$ We next assessed this hypothesis in our model. We measured the kinetic of these network modifications induced by PpIX and Hy treated cells. Under a constant laser illumination at 405/488/560 nm, live recordings of ER and mitochondrial networks are achieved on PpIX-loaded LNC25 (PpIX), Hy-loaded LNC25 (Hy) and PpIX-Hy-loaded LNC25 (PpIX+Hy) treated Hela cells for $2 \mathrm{~h}$. As reported in Figure 8A, ER network undergone fragmentation leading to ER vesicularization within a minute timescale. By comparison, the fragmentation of the mitochondrial network occurred within a period of $20 \mathrm{~min}$ (Figure S10). 
(A)

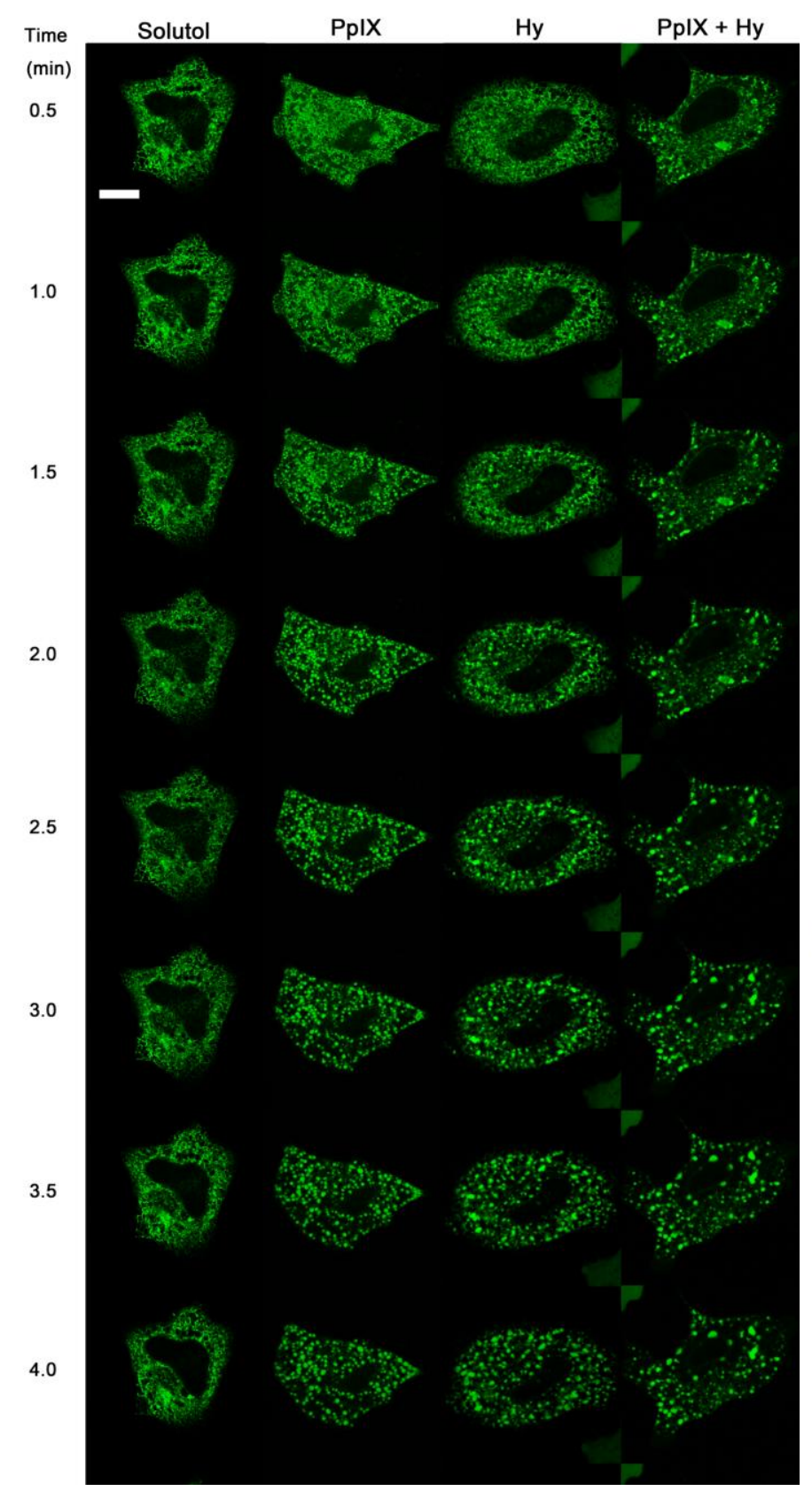

(B)

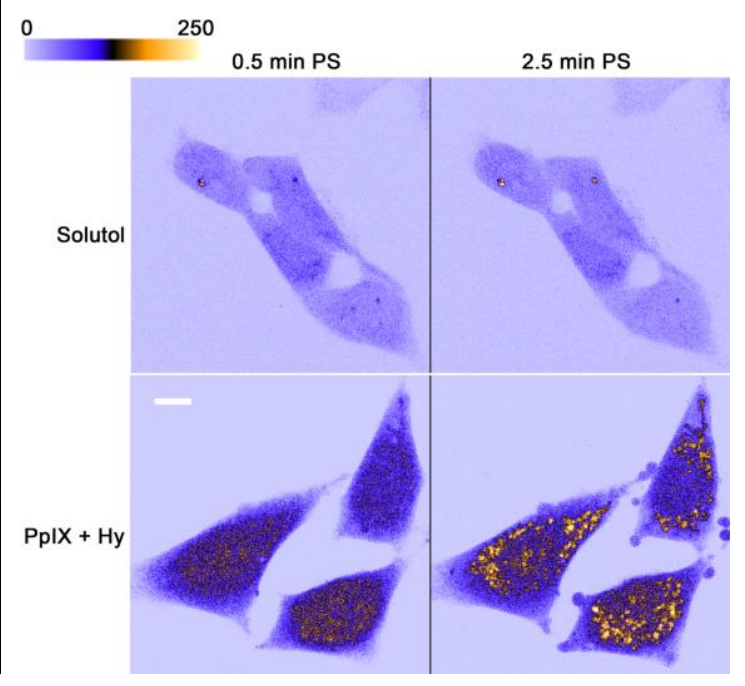

Figure 8. Modification in the structure of ER network in HeLa cells treated with PpIX-loaded LNC25 (PpIX), Hy-loaded LNC25 (Hy) and PpIX-Hy-loaded LNC25 (PpIX + Hy) upon illumination with a Laser at 405, 488 and $590 \mathrm{~nm}(\mathbf{A})$. Objective: $\times 60$. Scale bar: $5 \mu \mathrm{m}$. The main ROS production in (PpIX + Hy)-loaded Hela cells occurs in ER (B). Cells were incubated with $0.5 \mu \mathrm{M}$ PpIX-Hy-loaded LNC25 (PpIX + Hy) for $2 \mathrm{~h}$ before to be loaded with 2',7'dichlorofluorescin diacetate (H2DCFDA). Cells were illuminated with a Laser at 405, 488 and 
$590 \mathrm{~nm}$ while recording fluorescence images with the 488 laser line. Objective: $\times 60$. Scale bar: 5 $\mu \mathrm{m}$.

The high reactivity of ${ }^{1} \mathrm{O}_{2}$ with its local environnement highly restrictes its diffusion. The faster kinetic of ER fragmentation than the kinetic of mitochondria fragmentation, upon PS entrapment, suggests that ER membranes are one of primary sites of photostimulated singlet oxygen production by PpIX and Hy in Hela cells. Moreover, a recent study suggested that ROS are implicated as an inducer of ER fragmentation. ${ }^{44}$ We measured ROS production with the DFC probe in cells loaded concomitantly with PpIX and Hy. As shown in Figure 8B, the fluorescence increased in fragmented organnels that looked similar to the fragmented ER (Figure 8A). This suggests that ${ }^{1} \mathrm{O}_{2}$ production via PpIX and Hy could in turn induce ROS generation in the ER compartment, leading to its fragmentation. The slight difference of kinetics of ER fragmentation between encapsulated PpIX- $(2 \pm 0.5 \mathrm{~min})$ and Hy-loaded cells $(6 \pm 1 \mathrm{~min})$ could originate from their rates of ${ }^{1} \mathrm{O}_{2}$ production and/or their concentrations in ER membranes. It should also be noted that ER fragmentation is accompagned with a massive blebbing of the plasma membrane (Figure S11) within a similar period of time. Membrane blebbing is known to involve the rupture of tension forces between cytosqueletton and juxta-membranar protein coating, ${ }^{43}$ and can be triggered by an oxidative stress. ${ }^{45}$

In vivo applications of photosynthesizer nanocompositions. With the aim to utilize the observed toxic effect caued by combination of two photosynthesizers in nanocapsules we performed analysis on how the studied compounds are distributed in the body during different type of injection. For this reason swiss nude mice were injected with $100 \mu \mathrm{L}$ of Hy-loaded LNC25 (1.25 mg/kg of Hy) subcutaneously (s.c.), intravenously (into the tail vein, i.v.) or intraperitoneally (i.p.). Since studied compounds possess fluorescent properties they were easily 
monitored in the body of hairless mice using InVivo Extreme fluorescent scanner (Bruker). We observe a strong fluorescent signal, attributable to hypericine (ex. $540 \mathrm{~nm}$, em $600 \mathrm{~nm}$ ) at the place of subcutaneous injection and around the place of injection during intraperitoneal injection. (Figure 9A). In the next step we injected Hy-loaded LNC25 i.v. and i.p. and sacrificed the animal $2 \mathrm{~h}$ post injection, main organs were removed and accumulation of hypericine was analysed. During intravenous injection, we have observed fluorescent signal in intestine, gallbladder, liver and urinary bladder. This indicates that nanocapsules in the blood are removed by both kidney filtration (less extent) and conjugation in liver with subsequent excretion into bile and then into intestine (main part of compounds) (Figure 9B). In contrast, at the place of subcutaneous injection, we observed strong retention of LNC-Hy signal, while during subcutaneous injection we observed retention of Hy nanocapsules in the place of injection and in the close vicinity (like adipose tissue, subcutaneous tissue, skin). Thus we decided to choose intratumor injection as the best administration route for LNC-Hy. 

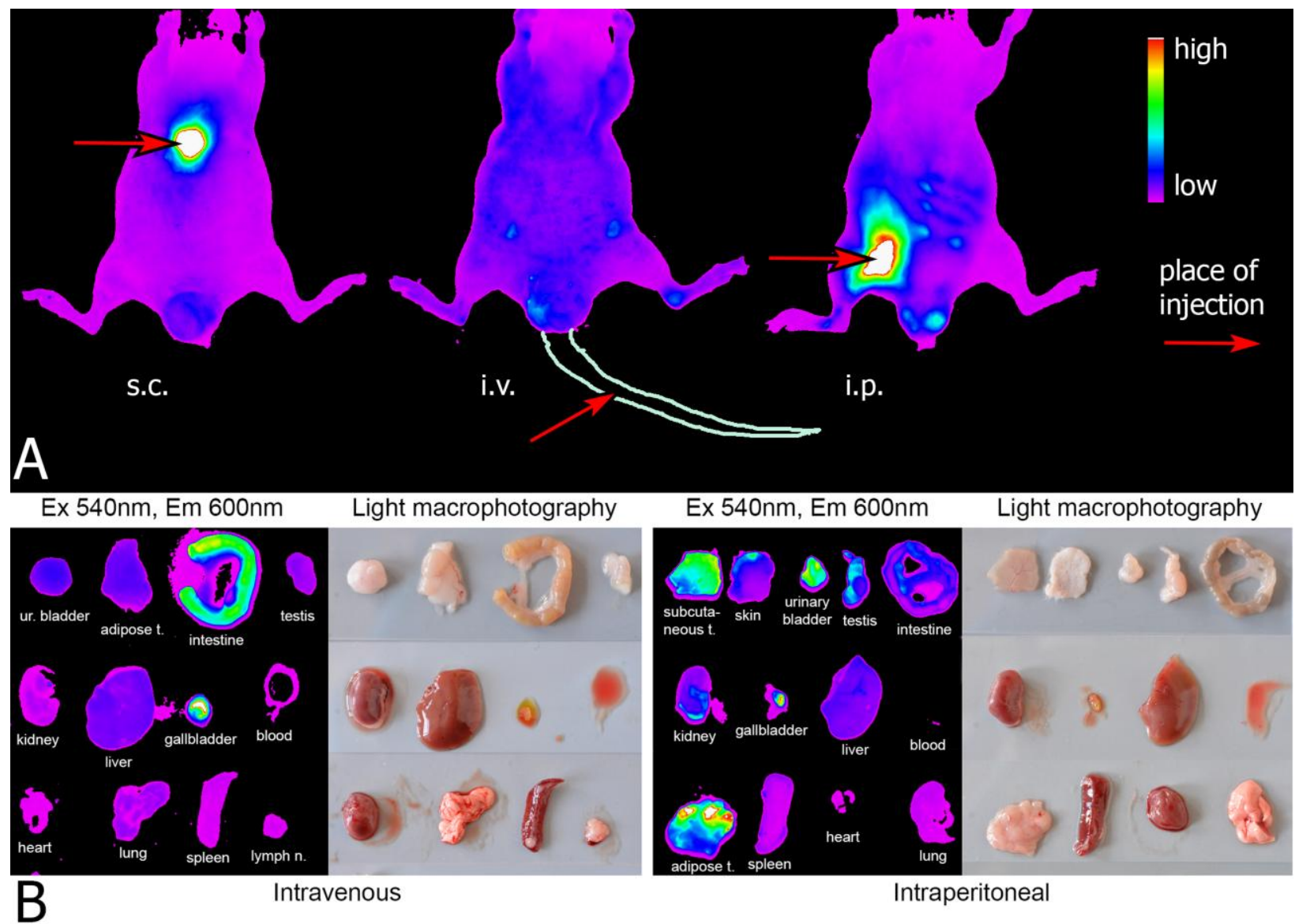

Figure 9. Biodistribution of LNC-Hy solution in the body. Distribution in the body of nude swiss mice $2 \mathrm{~h}$ after different types of injections: subcutaneous (s.c.), intravenous (i.v.), intraperitoneal (i.p.) (A). Distribution in different organs $2 \mathrm{~h}$ after intravenous or intraperitoneal injection (B). Fluorescence images were obtained by Bruker In-Vivo Extreme imager using ex. $540 \mathrm{~nm}$ and em. $600 \mathrm{~nm}$.

Mice were inoculated with $1.2 \times 106$ cells tumor cells in Matrix gel and allowed solid xenograft tumors to develop for 30 days, which become visible under the skin. Then we injected the studied compounds intratumorally and performed the irradiation with visible light $(\lambda>400 \mathrm{~nm}$, $0.35 \mathrm{~W}$ ) for 6 min course of light treatment. Tumor growth was monitored till day 53. Obtained data demonstrated a delayed tumor growth in case of treatment of LNC-PpIX-Hy (Figure 10). 


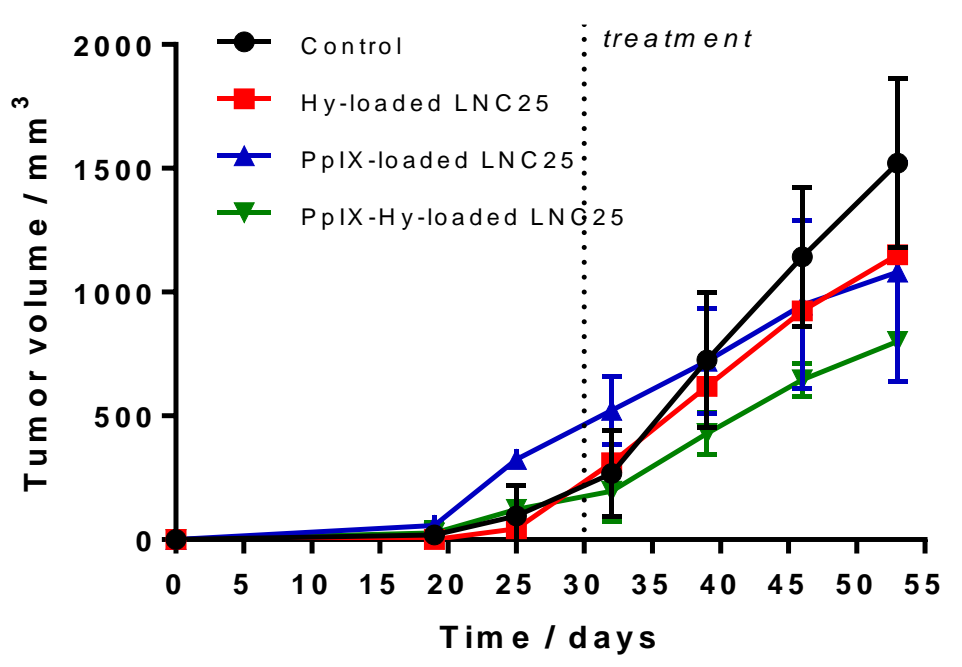

Figure 10. Growth of PC3-M tumor xenografts in swiss nude mice. At day 30 after the development of tumors, they were injected with studied compounds, treated with visible light $(\lambda>400 \mathrm{~nm}, 0.35 \mathrm{~W})$ for $6 \mathrm{~min}$ and tumor growth was further monitored till day 53.

The ability of LNCs containing the two PS molecules to retard tumor growth at the place of injection along with the mechanism of LNCs action, involving enhanced ROS production and the fact that tumor cells are characterized by increased ROS levels, ${ }^{46}$ open the possibility for coand/or post-operative treatment. Additionally, during tumor removal, there are always some tumor cells left, which are difficult to differentiate from living cells. These cells could become potentially the main source of resistant and recurrent metastatic tumors. Thus local application of LNCs upon tumor removal and subsequent controlled PDT should theoretically produce ROS levels which are quite tolerable to cells with low internal ROS production (non-tumorigenic) but those able to exhaust antioxidant system of cells with high internal ROS levels (tumor cells) and eventually kill them. Beside, application in other hard-to reach places like inside blood-brainbarrier could be another therapeutic target. Besides, the nanocomposition of LNCs allows their functionalization with more soluble compounds like phospholipids and sialic acid, both 
enhancing lifespan ${ }^{47}$ and ensuring cell targeting approaches, ${ }^{48}$ and/or with specific targeting molecules (antibodies).

\section{CONCLUSION}

Our results characterized several important modifications in cell physiology, which are induced by photo-sensitization using PpIX and Hy encapsulated in lipid nanocapsules (LNC25). Namely, we characterized cell cycle arrest, ER fragmentation and plasma membrane blebbing. Our results also highlight a strong discrepency in localization of PpIX and Hy whenever they are combined in the same LNC. We believe that the specific properties (rate of ${ }^{1} \mathrm{O}_{2}$ production, yield, absorbance) and subcellular localization of PpIX and Hy strongly improve the final efficiency of the phototherapy. This consequently gives the opportunity to decrease their respective concentration that is required to limite side effects. Nanocapsules were perfectly retained in the tissues at the place of injection, and subsequent light treatment demonstrated beneficial effect of LNCs on xenograft tumor growth retardation. Taking the advantage of the specific properties of different PSs and different subcellular targets, associated with targeting cancerous cells through LNC functionalization may strongly improve the PDT efficiency while minimizing the dark effects. 


\section{ACKNOWLEDGMENT}

N.S., A.B., S.S. and Ra.B gratefully acknowledge financial support from the Centre National de la Recherche Scientifique (CNRS), the Université Lille 1 and the Hauts-de-France region. S.S., T.D., S.P., Ro.B. acknowledge financial support from EUH2020-MSCE-RISE-2015 project no. 690836 PANG. We thank Profs P. Woisel and J. Lyskawa (Laboratoire de Chimie Macromoléculaire, UMR CNRS 8009) for technical support with fluorescence measurements.

\section{Contributions}

Experiments were designed by A.B. T.G., and Ra.B. Lipid nanocapsules synthesis, characterizations and in vitro experiments were performed by A.B. and N.D. Microscopy experiments were designed by G.B. and L.H. Microscopy experiments were performed by A.B., M.G.P., and G.B. In vivo experiments were designed by A.B., V.L. and Ro.B. In vivo experiments were performed by S.P., T.D., and A.U. The paper was written by A.B., H.B., Ro.B., S.S., G.B. and Ra.B. All authors have given approval to the final version of the manuscript.

\section{Competing interests}

The authors declare no competing financial interests.

\section{Corresponding authors}

Correspondance to Alexandre Barras and Rabah Boukherroub.

\section{SUPPORTING INFORMATION}

1. Supporting information

Supporting Figures 1-11. 


\section{REFERENCES}

1. T. J. Dougherty, C. J. Gomer, B. W. Henderson, G. Jori, D. Kessel, M. Korbelik, J. Moan and Q. Peng, J. Natl. Cancer Inst., 1998, 90, 889-905.

2. I. Yoon, J. Z. Li and Y. K. Shim, Clin. Endosc., 2013, 46, 7-23.

3. R. W. Redmond and J. N. Gamlin, Photochem. Photobiol., 1999, 70, 391-475.

4. R. Hudson, M. Carcenac, K. Smith, L. Madden, O. J. Clarke, A. Pelegrin, J. Greenman and R. W. Boyle, Br. J. Cancer, 2005, 92, 1442-1449.

5. M. F. Zuluaga and N. Lange, Curr. Med. Chem., 2008, 15, 1655-1673.

6. X. Schneider-Yin, A. Kurmanaviciene, M. Roth, M. Roos, A. Fedier, E. I. Minder and H. Walt, Photodiagnosis Photodyn. Ther., 2009, 6, 12-18.

7. E. Besic Gyenge, P. Forny, D. Luscher, A. Laass, H. Walt and C. Maake, Photodiagnosis Photodyn. Ther., 2012, 9, 321-331.

8. E. B. Gyenge, D. Luscher, P. Forny, M. Antoniol, G. Geisberger, H. Walt, G. Patzke and C. Maake, Photochem. Photobiol., 2013, 89, 150-162.

9. P. Acedo, J. C. Stockert, M. Canete and A. Villanueva, Cell Death Dis., 2014, 5, e1122.

10. A. Barras, L. Boussekey, E. Courtade and R. Boukherroub, Nanoscale, 2013, 5, 1056210572 .

11. S. Wang, R. Gao, F. Zhou and M. Selke, J. Mater. Chem., 2004, 14, 487-493.

12. T. A. Debele, S. Peng and H. C. Tsai, Inter. J. Mol. Sci., 2015, 16, 22094-22136.

13. B. Heurtault, P. Saulnier, B. Pech, J. E. Proust and J. P. Benoit, Pharm. Res., 2002, 19, 875-880.

14. I. Kraljic and S. El Mohsni, Photochem. Photobiol., 1978, 28, 577-581. 
15. F. Liu, X. Zhou, Z. Chen, P. Huang, X. Wang and Y. Zhou, Mater. Lett., 2008, 62, 28442847.

16. M. C. DeRosa, et al.,, Coord. Chem. Rev., 2002, 233-234, 351-371.

17. M. Hoebeke and X. Damoiseau, Photochem. Photobiol. Sci., 2002, 1, 283-287.

18. V. Sackova, P. Fedorocko, B. Szilardiova, J. Mikes and J. Kleban, Photochem. Photobiol., 2006, 82, 1285-1291.

19. T. Yang, M. K. Choi, F. D. Cui, J. S. Kim, S. J. Chung, C. K. Shim and D. D. Kim, J. Control. Release, 2007, 120, 169-177.

20. T. Perrier, P. Saulnier, F. Fouchet, N. Lautram and J. P. Benoit, Int. J. Pharm., 2010, 396, 204-209.

21. H. Weitman, M. Roslaniec, A. A. Frimer, M. Afri, D. Freeman, Y. Mazur and B. Ehrenberg, Photochem. Photobiol., 2001, 73, 110-118.

22. Y.-F. Ho, M.-H. Wu, B.-H. Cheng, Y.-W. Chen and M.-C. Shih, BBA-Biomembranes, 2009, 1788, 1287-1295.

23. A. B. Lamprecht, Y and Benoit, JP, J. Control. Release, 2002, 84 59-68.

24. A. Barras, A. Mezzetti, A. Richard, S. Lazzaroni, S. Roux, P. Melnyk, D. Betbeder and N. Monfilliette-Dupont, Int. J. Pharm., 2009, 379, 270-277.

25. E. I. Kapinus, H. Falk and H. T. N. Tran, Monatsh. Chem., 1999, 130, 623-635.

26. F. Gai, M. J. Fehr and J. W. Petrich, J. Phys. Chem., 1994, 98, 5784-5795.

27. T. Yamazaki, N. Ohta, I. Yamazaki and P. S. Song, J. Phys. Chem., 1993, 97, 7870-7875.

28. L. M. Scolaro, M. Castriciano, A. Romeo, S. Patanè, E. Cefali and M. Allegrini, J. Phys. Chem. B, 2002, 106, 2453-2459. 
29. G. Bano, J. Stanicova, D. Jancura, J. Marek, M. Bano, J. Ulicny, A. Strejckova and P. Miskovsky, J. Phys. Chem. B, 2011, 115, 2417-2423.

30. J. Qian, A. Gharibi and S. He, J. Biomed. Opt., 2009, 14, 014012.

31. F. C. Rossetti, L. V. Depieri, A. C. Tedesco and M. V. L. B. Bentley, Braz. J. Pharm. Sci., 2010, 46, 753-760.

32. M. B. Ericson, S. Grapengiesser, F. Gudmundson, A. M. Wennberg, O. Larko, J. Moan and A. Rosen, Lasers Med. Sci., 2003, 18, 56-62.

33. H. Bouirig, D. Eloy and P. Jardon, J. Chim. Phys. Phys.-Chim. Biol., 1993, 90, 20212038.

34. B. Ehrenberg, J. L. Anderson and C. S. Foote, Photochem. Photobiol., 1998, 68, 135-140.

35. M. Roslaniec, H. Weitman, D. Freeman, Y. Mazur and B. Ehrenberg, J. Photochem. Photobiol. B, 2000, 57, 149-158.

36. A. P. Darmanyan, L. Burel, D. Eloy and P. Jardon, J. Chim. Phys. Phys.-Chim. Biol., 1994, 91, 1774-1785.

37. C. Emiliani and M. Delmelle, Photochem. Photobiol., 1983, 37, 487-490.

38. K. Plaetzer, B. Krammer, J. Berlanda, F. Berr and T. Kiesslich, Lasers Med. Sci., 2009, 24, 259-268.

39. R. R. Allison, G. H. Downie, R. Cuenca, X. H. Hu, C. J. Childs and C. H. Sibata, Photodiagnosis Photodyn. Ther., 2004, 1, 27-42.

40. R. S. Ray, S. F. Mujtaba, A. Dwivedi, N. Yadav, A. Verma, H. N. Kushwaha, S. K. Amar, S. Goel and D. Chopra, Toxicology, 2013, 314, 229-237.

41. P. Perucca, M. Savio, O. Cazzalini, R. Mocchi, C. Maccario, S. Sommatis, D. Ferraro, R. Pizzala, L. Pretali, E. Fasani, A. Albini and L. A. Stivala, J. Photochem. Photobiol. B, 2014, 140, 57-68. 
42. V. Senthil, L. R. Jones, K. Senthil and L. I. Grossweiner, Photochem. Photobiol., 1994, 59, 40-47.

43. K. P. Uberriegler, E. Banieghbal and B. Krammer, Photochem. Photobiol., 1995, 62, 1052-1057.

44. F. X. Bao, H. Y. Shi, Q. Long, L. Yang, Y. Wu, Z. F. Ying, D. J. Qin, J. Zhang, Y. P. Guo, H. M. Li and X. G. Liu, CNS Neurosci. Ther., 2016, 22, 648-660.

45. R. M. van Gorp, J. L. Broers, C. P. Reutelingsperger, N. M. Bronnenberg, G. Hornstra, M. C. van Dam-Mieras and J. W. Heemskerk, Am. J. Physiol., 1999, 277, C20-28.

46. S. Daum, M. S. V. Reshetnikov, M. Sisa, T. Dumych, M. D. Lootsik, R. Bilyy, E. Bila, C. Janko, C. Alexiou, M. Herrmann, L. Sellner and A. Mokhir, Angew. Chem. Int. Ed., 2017, 56, 15545-15549.

47. A. Tomin, T. Dumych, Y. Tolstyak, I. Kril, I. Mahorivska, E. Bila, R. Stoika, M. Herrmann, Y. Kit and R. Bilyy, Clin. Exp. Immunol., 2015, 179, 17-23.

48. B. Chen, Y. Sun, J. Niu, G. K. Jarugumilli and X. Wu, Cell. Chem. Biol., 2018, DOI: 10.1016/j.chembiol.2018.05.003. 